\title{
Evidence of Mitochondrial Dysfunction in Fibromyalgia: Deviating Muscle Energy Metabolism Detected Using Microdialysis and Magnetic Resonance
}

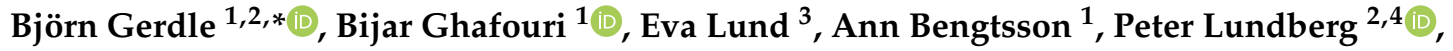 \\ Helene van Ettinger-Veenstra ${ }^{1,2}$, Olof Dahlqvist Leinhard ${ }^{2,4,5}$ and Mikael Fredrik Forsgren 2,4,5 \\ 1 Pain and Rehabilitation Centre, and Department of Health, Medicine and Caring Sciences, \\ Linköping University, SE 58183 Linköping, Sweden; bijar.ghafouri@liu.se (B.G.); \\ annbengtsson@yahoo.se (A.B.); helene.veenstra@liu.se (H.v.E.-V.) \\ 2 Center for Medical Image Science and Visualization (CMIV), Linköping University, \\ SE 58183 Linköping, Sweden; peter.lundberg@liu.se (P.L.); olof.dahlqvist.leinhard@liu.se (O.D.L.); \\ mikael.f.forsgren@liu.se (M.F.F.) \\ 3 Radiation Physics, Department of Health, Medicine and Caring Sciences, Linköping University, \\ SE 58183 Linköping, Sweden; eva.lund@liu.se \\ 4 Radiation Physics, Department of Health, Medicine and Caring Sciences, \\ SE 58183 Linköping University \& Department of Radiation Physics, UHL, SE 58185 Linköping, Sweden \\ 5 AMRA Medical AB, SE 58222 Linköping, Sweden \\ * Correspondence: bjorn.gerdle@liu.se; Tel.: +46-763927191
}

Received: 10 October 2020; Accepted: 30 October 2020; Published: 31 October 2020

\begin{abstract}
In fibromyalgia (FM) muscle metabolism, studies are sparse and conflicting associations have been found between muscle metabolism and pain aspects. This study compared alterations in metabolic substances and blood flow in erector spinae and trapezius of FM patients and healthy controls. FM patients $(n=33)$ and healthy controls $(n=31)$ underwent a clinical examination that included pressure pain thresholds and physical tests, completion of a health questionnaire, participation in microdialysis investigations of the etrapezius and erector spinae muscles, and also underwent phosphorus-31 magnetic resonance spectroscopy of the erector spinae muscle. At the baseline, FM had significantly higher levels of pyruvate in both muscles. Significantly lower concentrations of phosphocreatine ( $\mathrm{PCr}$ ) and nucleotide triphosphate (mainly adenosine triphosphate) in erector spinae were found in FM. Blood flow in erector spinae was significantly lower in FM. Significant associations between metabolic variables and pain aspects (pain intensity and pressure pain threshold PPT) were found in FM. Our results suggest that FM has mitochondrial dysfunction, although it is unclear whether inactivity, obesity, aging, and pain are causes of, the results of, or coincidental to the mitochondrial dysfunction. The significant regressions of pain intensity and PPT in FM agree with other studies reporting associations between peripheral biological factors and pain aspects.
\end{abstract}

Keywords: fibromyalgia; chronic pain; muscle; microdialysis; ATP; PCr; magnetic resonance spectroscopy; magnetic resonance imaging

\section{Introduction}

Pain arises in the brain because of influences from neurobiological, psychological, and social/contextual aspects and their complex interactions. Fibromyalgia (FM) is characterized by chronic widespread pain and often generalized hyperalgesia/allodynia. Depending on the 
diagnostic criteria, FM has a prevalence of $2-8 \%$. FM is associated with high comorbidity for other chronic pain conditions and somatic and psychological symptoms/disorders. No definite pathophysiology has been established. Imaging techniques have challenged previous ideas about the peripheral origin of FM and have provided evidence for altered central nervous system (CNS) nociceptive/pain processing and morphology in FM. However, recent studies have reported both central alterations and peripheral alterations (e.g., systemic low-grade inflammation and nociceptor/muscle alterations) [1-5]. Understanding these complicated peripheral and central processes and their interactions are fundamental for developing treatments.

In real life muscle work, several fuels are used to produce adenosine triphosphates (ATPs), the cell's energy currency [6]. The fuels-mainly carbohydrates (plasma glucose and muscle glycogen) and fats (plasma free fatty acids and muscle triglycerides), but also amino acids-are used by muscle cells to produce ATPs [6-8].

To analyze muscle metabolism, several FM studies have used microdialysis (MD), an in vivo technique, to collect substances from the muscle interstitium. Two MD studies of FM reported increased concentrations of lactate and/or pyruvate (i.e., products of glycolysis) in the trapezius $[9,10]$. Another FM study found that the concentrations of both lactate and pyruvate were significantly increased in the vastus lateralis [11]. One study of the trapezius found significant associations between these substances and pain intensity and PPT [10]; however, the two other studies failed to establish such significant correlations $[9,11]$.

${ }^{31} \mathrm{P}$ magnetic resonance spectroscopy $\left({ }^{31} \mathrm{P}-\mathrm{MRS}\right)$ can be used to non-invasively investigate phosphorous metabolism, carbohydrate metabolism, and intracellular $\mathrm{pH}$ in muscles [12] (i.e., mitochondrial function [13]). This method has been used by several FM studies, but findings are inconsistent (see Gerdle et al. [14]). This inconsistency is probably due to differences in the conditions investigated, differences in the type of muscle investigated, and whether absolute or relative measures of metabolism were used. The only two studies that determined absolute muscle concentrations of adenosine triphosphate (ATP) and phosphocreatine (also known as creatine phosphate (CP)) (PCr) in FM reported significantly lower levels in the quadriceps $[14,15]$. One of these studies found an association between ATP concentration and pain intensity just above the significance threshold $(p=0.057)$ [15], whereas the other study found no correlation between ATP and PCR and pain intensity [14].

This study is motivated by the fact that muscle metabolism is poorly investigated in FM patients, many FM patients have reported that their pain condition started and persists in neck-shoulder muscles and low back muscles, and that findings from previous studies are inconsistent with respect to FM associations with central factors such as pain intensity and PPT. To address these shortcomings, we compared alterations in metabolic status (including blood flow) in the erector spinae and trapezius of female FM patients and matched healthy controls. In addition, we investigated to what extent muscle metabolic status correlated with PPT, pain intensity, and physical performance. Thus, this relatively large study using different methods to capture the muscle metabolic status has potential to shed further light on pathophysiology in FM (i.e., possible mitochondrial involvement). Moreover, this study applied advanced multivariate methods, which can determine is muscle metabolic alterations are associated with pain aspects in FM with better precision than earlier studies.

\section{Subjects and Methods}

\subsection{Subjects}

This large-scale investigation of FM included 33 female FM patients and 31 age-matched female controls $(\mathrm{CON})$ between 22 and 56 years old. The CON group was recruited through advertisements in newspapers, and the FM group was recruited from former patients at the Pain and Rehabilitation Center at the University Hospital in Linköping. The number of subjects was determined using Power and Sample Size Calculation ver 3.0.2 [16] based on results from both microdialysis (the concentration of lactate according to Rosendal et al. [17]) and from ATP concentration obtained from spectroscopy 
of the vastus lateralis (Gerdle et al. [14]). Both analyses indicated that 25 subjects in each group were necessary. Of the 64 subjects recruited to this study, 62 participated in the ${ }^{31} \mathrm{P}-\mathrm{MRS}$ part and 57 participated in the MD part of the study. Details on the inclusion and exclusion criteria as well as clinical examination are given below.

The study was granted ethical clearances by Linköping University Ethics Committee (Dnr: 2016/239-31). All participants gave their written informed consent, and the study was performed in accordance with the Helsinki Declaration.

\subsection{Procedures}

At the first visit, the subjects underwent a clinical examination that included pain threshold tests and physical tests. In addition, the subjects completed a health questionnaire that covered aspects of pain, health, disability, demographic data, and psychological characteristics. At the second visit, the subjects underwent MD of the trapezius and the erector spinae muscles. At the third visit, spectroscopy was used to evaluate the subjects' erector spinae.

\subsection{Clinical Examinations}

Both FM patients and controls underwent a brief clinical examination of the heart and lungs, which included recording diastolic and systolic blood pressure $(\mathrm{mm} \mathrm{Hg})$ after two minutes of rest. In addition, their weight $(\mathrm{kg})$ and height $(\mathrm{m})$ were recorded. Using these measurements, Body Mass Index (BMI, $\mathrm{kg} / \mathrm{m}^{2}$ ) was calculated and classified according to the World Health Organization (WHO) criteria: $<18.5=$ underweight; $18.5-24.9=$ normal range; $25.0-29.9=$ overweight; $30.0-34.9$ = obesity; and $\geq 35.0=$ severe obesity. The clinical examination ensured that the controls were healthy with respect to anamnesis for rheumatic diseases, neurological diseases, diabetes, cardio-vascular diseases, psychiatric diseases, and high alcohol consumption (i.e., Alcohol Use Disorders Identification Test (AUDIT) $>6$ according to the recommendations for women).

The clinical examination of the patients ensured that they met the criteria for FM according to the 1990 criteria from the American College of Rheumatology (ACR) [18] and that they were not abusing alcohol (i.e., high alcohol consumption) according to AUDIT. The number of tender points were registered both in FM and in CON. The ACR criteria from 1990 is based on anamnestic reports and semi-objective examinations of hyperalgesia/allodynia (tender points). Newer criteria (2010/2011 and 2016) based on anamnestic reports have been established [19-21]. As we wanted to compare our study with earlier studies, we chose the ACR criteria from 1990.

\subsubsection{Pressure Pain Thresholds}

Pressure pain thresholds (PPT) were determined using a manual pressure algometer (Somedic $\mathrm{AB}$, Sweden) mounted with a probe (contact area of $1 \mathrm{~cm}^{2}$ ) on the muscle belly (for details, see [22,23]). The erector spinae, tibialis anterior, and trapezius were investigated bilaterally. The pressure was increased by $30 \mathrm{kPa} / \mathrm{s}$ until the subject perceived pain, indicated by pushing a stop button or until the maximum threshold of $600 \mathrm{kPa}$ was reached. The PPT for each anatomical location was defined as the mean of two trials obtained with a minimum interval of $30 \mathrm{~s}$. We used the mean of the six anatomical locations (PPT-tot) as well as PPT for the trapezius and erector spinae (i.e., the muscles that were assayed using MD).

\subsubsection{Physical tests}

Hand function

Grip force (N) was measured using Grippit (AB Detektor, Gothenburg, Sweden). Peak value (Grip force-max), average value (Grip force-average), and 10-s value (Grip force-endur) were recorded for $10 \mathrm{~s}$ for the dominant hand (for details, see our earlier study [14]). The test-retest precision has been 
shown to be high for peak and average values [24]. Mean values of dominant and non-dominant sides are presented.

Aerobic fitness test

The subjects were given a submaximal cycle ergometer aerobic fitness test to determine their $\mathrm{MaxVO}_{2}$ [25].

Lower extremity muscle performance

Lower extremity muscle performance was measured using the timed-stands test (TST) (i.e., the number of times the subjects stand up and sit down from a standard chair for $30 \mathrm{~s}[26,27])$.

\subsection{Questionnaire}

All subjects answered a questionnaire covering pain, health, distress, disability, background data, and psychological aspects.

\subsubsection{Pain aspects}

Patients reported the duration of FM (years). Global pain intensity the previous seven days was reported using a numeric rating scale (NRS) $(0=$ no pain and $10=$ worst possible pain).

Pain Sensitivity Questionnaire (PSQ): Pain sensitivity was assessed using the Pain Sensitivity Questionnaire (PSQ). The PSQ consists of 17 items that describe daily life situations. For each situation, the subjects rate how intense the pain (not aversiveness or distress) would be for them $(0=$ not painful at all and $10=$ worst pain imaginable) [28]. Of the 17 situations, 14 are normally considered painful (e.g., cold, sharp, and blunt pain) and the other three are not (e.g., taking a warm shower). The mean of the 14 painful items was calculated. The PSQ was translated into Swedish using an iterative forward-backward process [29]. Although the Swedish version of the PSQ has not been psychometrically evaluated, translations to other languages have shown satisfactory statistical properties [30-33].

\subsubsection{Psychological distress}

Hospital Anxiety and Depression Scale (HADS): The Hospital Anxiety and Depression Scale (HADS) is used frequently in clinical practice and research because of its good psychometric characteristics [34,35]. HADS includes two subscales: HADS-depression and HADS-anxiety. Both these subscales have seven items with a scoring range between 0 and 21. A lower score indicates a lower possibility of anxiety or depression. In this study, the total score (i.e., the sum of the two subscales) was used to capture psychological distress (0-42) [36].

Pain Catastrophizing Scale (PCS): The Pain Catastrophizing Scale (PCS) includes 13 items with five answering alternatives. The PCS captures different dimensions of catastrophizing such as rumination, magnification, and helplessness $[37,38]$. In the present study, the total PCS (PCS-total) was used; the maximum score was 52 .

Insomnia Severity Index: The Insomnia Severity Index (ISI), which has good internal consistency, captures the severity and impact of insomnia symptoms [39,40]. The seven items of the ISI are rated on a five-point Likert scale $(0-4)$ and a total score is calculated $(\max =28)$.

\subsubsection{Disability}

Pain Disability Index (PDI): The Pain Disability Index (PDI), which measures the impact that pain has on a person's ability to participate in essential life activities [41,42], consists of seven items and every item is rated on a 10-point scale. The items assess the perception of the specific impact of pain on disability that may preclude normal or desired performance of a wide range of functions such as sex, 
work, daily activities, family and social activities, and life support (sleeping, breathing, and eating). The ratings of these seven items are summed; that is, the PDI score ranges between 0 and 70 .

\subsubsection{Health aspects}

The European Quality of Life Instrument: The European Quality of Life Instrument (EQ-5D), which captures a patient's perceived state of health [43,44], consists of two parts. The first part is an index based upon five dimensions. In this study, however, we only used the second part: the self-estimation of today's health according to a 100-point thermometer-like scale (EQ-VAS) with defined end points (high values indicate good health and low values indicate bad health).

\subsection{Microdialysis and Sample Preparation}

Microdialysis (MD) mimics a capillary blood vessel by perfusing a thin dialysis tube implanted in the tissue with a physiological saline solution. By simple diffusion, molecules cross the dialysis membrane along the concentration gradient and the obtained dialysate can be analyzed chemically. MD allows for continuous sampling of compounds in the interstitial space of muscle, where the nociceptors are located, and provides information of local biochemical changes before such compounds are diluted and cleared by the circulatory system. The subjects were instructed not to perform strenuous exercise two days before the study and not to drink any beverages with caffeine nor smoke the day of the study. In addition, they were asked not to take paracetamol-medication two days before and Nonsteroidal anti-inflammatory drug (NSAID) medication one week before the MD sessions. All participants indicated that they had followed the instructions. The skin and the subcutaneous tissues above the entry point of the catheter were anesthetized with a local injection $(0.5 \mathrm{~mL})$ of lidocaine Xylocain $_{\mathbb{B}}$ $20 \mathrm{mg} / \mathrm{mL}$, AstraZeneca, Södertälje, Sweden) without adrenaline. Care was taken not to anesthetize the underlying muscle. A commercially available MD catheter (CMA 60; CMA Microdialysis AB, Solna, Sweden) was inserted parallel to the muscle fibers of the trapezius muscle and the erector spinae muscle. This catheter had a cut-off of $20 \mathrm{kDa}$, a membrane length of $30 \mathrm{~mm}$, and a diameter of $0.5 \mathrm{~mm}$. Typically, a brief involuntary contraction and change of resistance were perceived when the tip of the insertion needle of the catheter entered the fascia and the muscle. Before the insertion of the catheter, ultrasound measurements determined the distance between the skin and the muscle. In the trapezius, the catheter was inserted in the middle third of the upper part of the trapezius muscle lateral to medial. Using the landmarks presented by the project Surface EMG for non-invasive assessment of muscles (SENIAM), we identified the midpoint of the line between the spine of the seventh cervical vertebra and the acromion. This point was defined as the midpoint of the descending trapezius [45]. For the erector spinae (ES) muscle, the crista iliaca was identified and the catheter was inserted $2-3 \mathrm{~cm}$ above this level at the most prominent part of the erector spine in the caudal direction. The catheters were perfused with a high-precision syringe pump (CMA 107; CMA/Microdialysis AB, Stockholm, Sweden) at a rate of $5 \mu \mathrm{L} / \mathrm{min}$ with a Ringer acetate solution (Fresenius Kabi AB, Uppsala, Sweden) containing 3-mM glucose, 0.5-mM lactate, and 3.0- $\mu \mathrm{M}\left[{ }^{14} \mathrm{C}\right]$-lactate (specific activity: $5.81 \mathrm{GBq} / \mathrm{mmol}$, GE Healthcare, Buckinghamshire, UK). This procedure was performed according to the internal reference method [46]. Furthermore, nutritive muscle blood flow was estimated by the MD ethanol technique [47] using ${ }^{3} \mathrm{H}_{2} \mathrm{O}$ instead of ethanol [48]. In addition, $0.3-\mu \mathrm{l} / \mathrm{mL}^{3} \mathrm{H}_{2} \mathrm{O}$ (specific activity: $37 \mathrm{MBq} / \mathrm{g}$; PerkinElmer Life Sciences, Boston, MA, USA) was added to the perfusate. The ratio of ${ }^{3} \mathrm{H}_{2} \mathrm{O}$ in the dialysate and the perfusate (the outflow-to-inflow ratio) varies inversely with the local blood flow in the tissue $[47,48]$. In the present study, this ratio was inverted to indicate the blood flow and facilitate the interpretations.

Samples from both catheters were obtained every $20 \mathrm{~min}$ for the $220 \mathrm{~min}$ of testing and the samples were kept on ice throughout the MD experiment. The samples were then stored as aliquots at $-70^{\circ} \mathrm{C}$ until analysis. All vials were weighed before the experiment and after each 20-min interval to confirm that sampling and fluid recovery (FR) were working according to the perfusion rate set. Vials with visible signs of hemolysis were discarded. 
Immediately after the insertion of catheters, participants rested comfortably in an armchair for $120 \mathrm{~min}$ (i.e., the trauma period) to allow the tissue to recover from possible changes in the interstitial environment induced. After the trauma period, participants continued to rest for $20 \mathrm{~min}$, the baseline period (denoted $140 \mathrm{~min}$ ). The baseline period was followed by a 20 -min period of standardized repetitive low-force exercise of the neck-shoulder muscles sitting in a chair performed on a pegboard (denoted $160 \mathrm{~min}$ ). The experiment ended with a recovery period of $60 \mathrm{~min}$, during which participants rested in the armchair.

During the MD session, the subjects rated their pain intensity in the trapezius and erector spinae taken together from the most painful side (FM) or the dominant side (CON) every 20 min using an NRS (see above).

Analyses of metabolites: The dialysates gathered from each time point were thawed and centrifugalized. Next, the dialysates were analyzed for the interstitial concentrations of pyruvate, lactate, glutamate, glycerol, and glucose with a ISCUSS ${ }^{\text {flex }}$ Analyzer (CMA Microdialysis, Solna, Sweden; standard range). The detection intervals used were as follows: $0.1-12 \mathrm{mmol} \mathrm{L}^{-1}$ for lactate; $10-1500 \mu \mathrm{mol} \mathrm{L}^{-1}$ for pyruvate; $1.0-150 \mu \mathrm{mol} \mathrm{L}^{-1}$ for glutamate; $0.1-25 \mathrm{mmol} \mathrm{L}^{-1}$ for glucose; and $10-1500 \mathrm{mmol} \mathrm{L}^{-1}$ for glycerol.

Relative recovery (RR) measurements: A 5- $\mu \mathrm{L}$ dialysate or perfusate was pipetted into a counting vial containing 3-mL scintillation fluid (High-flash Point, Universal LSC-Cocktail, ULTIMA GOLD ${ }^{\mathrm{TM}}$, PerkinElmer, Inc., MA, USA) and vortexed. $\beta$-counting was performed using a liquid scintillation counter (Beckman LS 6000TA, Beckman instruments, Inc., Fullerton, CA, USA). RR was calculated as $\left(\mathrm{dpm}_{\mathrm{p}}-\mathrm{dpm}_{\mathrm{d}}\right) / \mathrm{dpm}_{\mathrm{p}}$, where $\mathrm{dpm}_{\mathrm{p}}$ and $\mathrm{dpm}_{\mathrm{d}}$ are disintegrations per minute in the perfusate and the dialysate, respectively.

Variables from MD: The MD investigations revealed blood flow, pain intensity, concentrations of the five metabolites at baseline (140 min) and after working the trapezius for $20 \mathrm{~min}$ (160 $\mathrm{min})$, the mean value of the time points from baseline to the end of the recovery (140-220 min), and the difference between the $160 \mathrm{~min}$ and $140 \mathrm{~min}$ registrations/concentrations. In addition, pain intensity was recorded for each catheter insertion.

\subsection{Magnetic Resonance Spectroscopy of Erector Spinae}

${ }^{31}$ P-MRS: ${ }^{31}$ P-MRS of erector spinae was acquired with a Philips Ingenia 3 Tesla MR-scanner. Spectroscopic measurements were performed using a manufacturer-provided ${ }^{31} \mathrm{P}$ transmit-receive surface coil with a diameter of $14 \mathrm{~cm}$. Spectra were acquired using a $42{ }^{\circ} \mathrm{C}$ block pulse for the spin excitation, $15 \mathrm{~s}$ repetition time (TR), $153.4 \mu \mathrm{s}$ echo time (TE), $3 \mathrm{kHz}$ bandwidth, 2048 datapoints, 16 averages, and two dummy scans.

A custom-built platform allowed the subjects to be examined in a supine head-first position while having both the MRS-coil as well as a cylindrical $(\mathrm{r}=50 \mathrm{~mm}, \mathrm{~h}=80 \mathrm{~mm})$ external reference filled with $85 \mathrm{mM}$ dimethyl methylphosphonate (DMMP) placed underneath the subject's spinal erectors (Figure 1). ${ }^{31}$ P-MRS Processing: For post-processing of the ${ }^{31} \mathrm{P}-\mathrm{MRS}$ data, jMRUI [49] was used with the AMARES algorithm in combination with prior knowledge [50] for relative quantification of the resonances. Phosphocreatine (PCr) was used as a chemical-shift reference assigned to the standard chemical shift of $-2.35 \mathrm{ppm}$, and other assignments were obtained from the literature as previously described [14]. Assignments are shown for the FM and CON groups in Figure 2.

In short, phosphomonoesters (PME) represented a combined signal from phosphoethanolamine (PEth) and phosphocholine (PCho); inorganic phosphate $\left(\mathrm{P}_{\mathrm{i}}\right)$ and $\mathrm{PCr}$ were all defined as singlets in jMRUI. The phosphodiester (PDE) resonance represented glycerophosphoetanolamine (GPEth) and glycerophosphocholine (GPCho). In addition, a resonance corresponding to $\mathrm{NAD}(\mathrm{H})$ was also observed. Finally, the nucleotide triphosphate (NTP-Mg or NTP for short, mainly composed of ATP saturated with $\left.\mathrm{Mg}^{2+}[\mathrm{Mg}-\mathrm{ATP}]\right)$ resonances were assigned and interpreted as $\alpha-, \beta-$, and $\gamma-\mathrm{NTP}-\mathrm{Mg}$ as previously reported [14]. $\mathrm{pH}$ was estimated in the spectra using the modified Henderson-Hasselbach 
equation to assess the chemical shift between $\mathrm{P}_{\mathrm{i}}$ and $\mathrm{PCr}$ (where $\mathrm{pK}_{\mathrm{A}}=6.77, \delta_{\mathrm{HA}}=3.23 \mathrm{ppm}$, and $\delta_{\mathrm{A}}=5.70 \mathrm{ppm}$ ) as described previously [51] using the built in functionality in jMRUI.

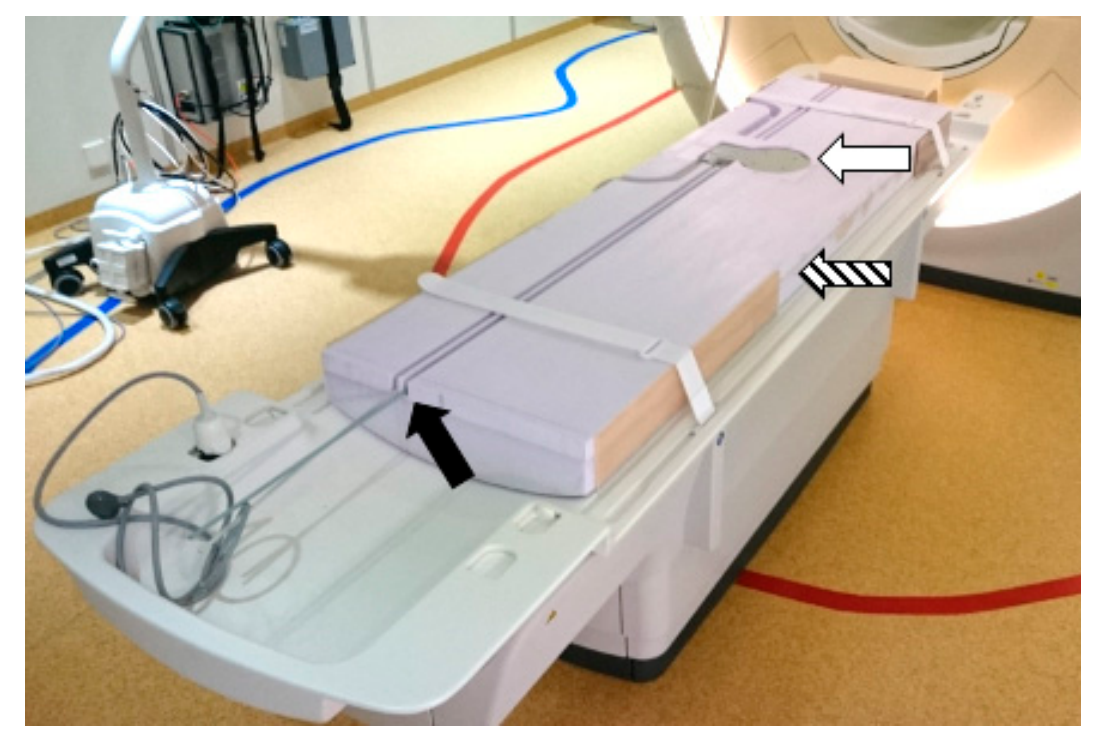

Figure 1. Experimental setup for measuring phosphorus-31 magnetic resonance spectroscopy (31P MRS) at $3 \mathrm{~T}$, within the spinal erectors. A custom platform was built (striped arrow) to fit on the scanner table. This platform allowed the participants to lie flat on their backs with the phosphorus transmit/receive coil lowered into the platform (white arrow). Underneath the coil, a cavity housed the external cylindrical reference. Spaces were also made for the tuning and matching control rods (black arrow).

${ }^{31}$ P-MRS Signal Processing: To correct for relaxation differences of the resonances, each quantized resonance was corrected according to Equation (1):

$$
\text { correction factor }=\frac{1}{1-\operatorname{Exp}\left(\frac{-T R}{T_{1}}\right)} \frac{1}{\operatorname{Exp}\left(\frac{-T E}{T_{2}}\right)},
$$

where TR and TE are specific to the ${ }^{31} \mathrm{P}$-MRS acquisition protocol and $\mathrm{T}_{1}$ and $\mathrm{T}_{2}$ are relaxation times of the resonances being corrected. The relaxation times were obtained from the literature [52], assuming $\beta$-NTP and PME have similar $T_{2}$ characteristics as $\alpha$-NTP and PDE, respectively.

Concentrations of NTP, PCr, and $\mathrm{P}_{\mathrm{i}}$ were estimated by defining a corrective factor based on the external DMMP reference as described previously [14]. During the study, the scanner required a major software upgrade and the ${ }^{31} \mathrm{P}$-coil, which was broken during the data collection phase, resulted in an increased signal-to-noise ratio (SNR) that had to be dealt with. For that reason, a correction factor for each set of software version and coil was implemented. Figure S1 shows the raw SNR of the external DMMP reference as well as the PCr for each subject before and after applying the correction for the upgraded scanner software and the new coil. In addition, ratios of the phosphorous metabolites were also calculated. Hence, the following spectroscopy variables were determined: $\mathrm{PCr}(\mathrm{mM}), \mathrm{P}_{\mathrm{i}}(\mathrm{mM})$, NTP (mainly ATP-Mg; in the following labelled ATP) (mM), pH, and the ratios ATP $/ \mathrm{P}_{\text {tot }}, \mathrm{PCr} / \mathrm{P}_{\text {tot }}$, $\mathrm{P}_{\mathrm{i}} / \mathrm{P}_{\text {tot }}, \mathrm{ATP} / \mathrm{PCr}$, and $\mathrm{Pi} / \mathrm{PCr}$. 

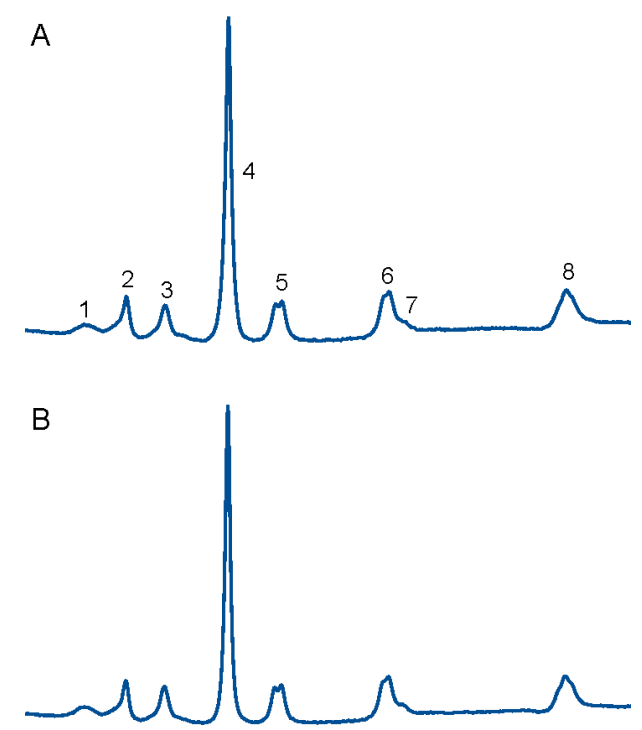

C

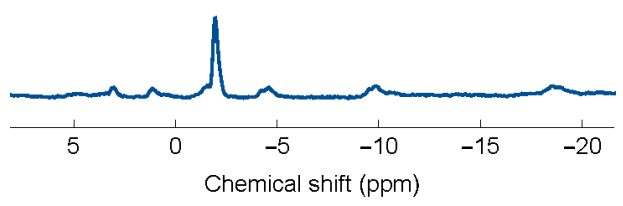

Figure 2. Spectra corresponding to the mean for the (A) control group $(n=30)$ and the corresponding (B) patient group with fibromyalgia $(n=32)$ in the spinal erectors at 3 T. Spectra are all normalized in Table (1) Phosphomonoesters(PME), (2) inorganic phosphate (Pi), (3) phosphodiesters (PDE), (4) phosphocreatine (PCr), (568) $\gamma, \alpha$, and $\beta$-nucleotide triphosphate (mainly Mg-saturated ATP), and $(7) \operatorname{NAD}(\mathrm{H}) .(\mathbf{C})$ The difference between the two groups of subjects.

\subsection{Statistics}

The statistics were performed using the statistical packages IBM SPSS Statistics (version 24.0; IBM Corporation, Route 100 Somers, New York, USA) and SIMCA-P+ (version 15.0; Sartorius Stedim Biotech, Umeå, Sweden). A $P$-value $<0.05$ was considered statistically significant. Text and tables report the mean value \pm one standard deviation $( \pm 1 \mathrm{SD})$ of continuous variables, and percentages $(\%)$ are reported for categorical variables. To compare groups, we used the Student's t-test for un-paired observations and the Chi square test for proportions. Previous studies have discussed the necessity of using advanced multivariate analyses (MVDA) when accounting for system-wide aspects including missing data and multicollinearity problems [53]. Using SIMCA-P+, we applied advanced principal component analysis (PCA) to determine multivariate outliers and orthogonal partial least square regressions (OPLS) to determine multivariate associations. These techniques do not require normal distributions of the included variables [54]. SIMCA-P+ uses the non-linear iterative partial least squares (NIPALS) algorithm to handle missing data: max 50\% missing data for variables/scales and max $50 \%$ missing data for subjects. In the present study, PCA was used to determine multivariate outliers. PCA extracts and displays systematic variation in the data matrix (i.e., a kind of multivariate correlation analysis). If data were skewed, variables were log transformed before the statistical analyses. A cross validation technique was used to identify nontrivial components (p). Variable loadings on the same component $\mathrm{p}$ were correlated, and variables with high loadings but opposing signs were 
negatively correlated. Variables with high absolute loadings were considered significant. Per definition, the obtained components are not correlated and are arranged in decreasing order with respect to explained variation. $R^{2}$ describes the goodness of fit, the fraction of the sum of squares of all the variables explained by a principal component [55]. $Q^{2}$ describes the goodness of prediction, the fraction of the total variation of the variables that can be predicted using principal component cross validation methods [55]. Outliers were identified using two methods: score plots in combination with Hotelling's $\mathrm{T}^{2}$ and distance to model in X-space. In the present study, one strong multivariate outlier (a control subject-study ID 115) was identified and excluded from the multivariate analyses.

OPLS-discriminant analysis (OPLS-DA) was made for multivariate group analysis. OPLS was used for the multivariate regression analyses of pain intensity, PPTs over trapezius and erector spinae, physical tests and blood flow using the data obtained from the ${ }^{31} \mathrm{P}-\mathrm{MRS}$, and MD examinations (except the pain intensity variables from the MD examination). The variable influence on projection (VIP) indicates the relevance of each $\mathrm{X}$-variable pooled over all dimensions and $\mathrm{Y}$-variables, the group of variables that best explains Y [55]. VIP > 1.0 was considered significant if VIP had a 95\% jack-knife uncertainty confidence interval non-equal to zero. $\mathrm{P}$ (corr) was used to note the direction of the relationship (positive or negative) (i.e., the loading of each variable was scaled as a correlation coefficient and therefore standardized the range from -1 to +1 [54]). $\mathrm{P}($ corr $)$ is stable during iterative variable selection and comparable between models. An absolute $p$ (corr) of $\geq 0.50$ was considered statistically significant [54]. Thus, a variable/regressor was considered statistically significant when VIP $>1.0$ and absolute $\mathrm{p}(\mathrm{corr}) \geq 0.50$. A regression model will be obtained including one or several components (the first is always the predictive component) if certain predefined criteria are fulfilled. The validity of the model is estimated using cross validation. Hence, for each regression, we report $\mathrm{R}^{2}$, $\mathrm{Q}^{2}$, and the $P$-value of a cross-validated analysis of variance (CV-ANOVA). The OPLS analysis was made in two steps. In the first step, all variables were included in the analysis. In the second step, the variables with VIP $\geq 1.0$ were used in a new OPLS regression. The results of the second (final) regression in the text and tables are given as $\mathrm{R}^{2}, \mathrm{Q}^{2}$, and $P$-value of CV-ANOVA. The tables present the regressors with VIP $>1.0$ and absolute $p($ corr $) \geq 0.50$.

\section{Results}

\subsection{Data from Questionnaires and Clinical Examinations}

Significant group differences were found in disability, catastrophizing, insomnia severity, psychological distress, perceived pain sensitivity, and health-related quality of life (Table 1).

Table 1. Data obtained from questionnaires in controls and in patients with fibromyalgia (FM).

\begin{tabular}{cccccccc}
\hline Group & CON & & & FM & & Statistics \\
\hline Variables & $n$ & Mean & SD & $n$ & Mean & SD & $p$-value \\
\hline Age (years) & 31 & 42.26 & 10.17 & 33 & 40.06 & 11.36 & 0.417 \\
FM duration (years) & - & - & - & 33 & 6.12 & 6.04 & NA \\
Pain intensity & - & - & - & 31 & 6.55 & 1.71 & NA \\
global 7days & 31 & 4.23 & 3.59 & 31 & 13.32 & 6.17 & $<0.001^{*}$ \\
HADS & 31 & 11.45 & 8.97 & 31 & 19.94 & 10.34 & $0.001^{*}$ \\
PCS & 31 & 4.23 & 4.47 & 31 & 13.58 & 5.96 & $<0.001^{*}$ \\
ISI & 31 & 3.50 & 0.91 & 31 & 5.64 & 1.80 & $<0.001^{*}$ \\
PSQ & 30 & 8.43 & 4.93 & 31 & 36.45 & 11.25 & $<0.001^{*}$ \\
PDI & 30 & 86.67 & 7.54 & 31 & 52.16 & 18.85 & $<0.001^{*}$ \\
EQ5D-VAS & &
\end{tabular}

$\mathrm{CON}$ = controls; FM = fibromyalgia; $\mathrm{SD}$ = standard deviation; HADS = The Hospital Anxiety and Depression Scale; PCS = Pain Catastrophizing Scale; ISI = Insomnia Severity Index, PSQ-total = Pain Sensitivity Questionnaire-total scale; PDI = Pain Disability Index; EQ5D-VAS = Perceived Health according to EQ instrument; NA = Not Applicable.

* denotes statistical significance. 
In addition, significant differences were found in blood pressure and anthropometric variables (Table 2): FM had somewhat higher blood pressures and higher BMI. In FM, the BMI classes were $30.3 \%$ normal weight, $27.3 \%$ overweight, and $42.4 \%$ obese/severe obese; in CON, the BMI classes were $71.0 \%$ normal weight, $22.6 \%$ overweight, and $6.5 \%$ obese/severe obese $\left(\mathrm{Chi}^{2}=13.7, \mathrm{df}=1 ; p<0.001\right)$. The measures of pain sensitivity (i.e., hyperalgesia/allodynia) also showed significant differences; in FM, PPT was lower and number of tender points higher. TST, aerobic capacity, and grip force aspects were significantly lower in FM (Table 2).

Table 2. Variables obtained at the clinical examinations.

\begin{tabular}{|c|c|c|c|c|c|c|c|}
\hline Group & $\mathrm{CON}$ & & & FM & & & Statistics \\
\hline Variables & $n$ & Mean & SD & $n$ & Mean & SD & $p$-value \\
\hline Blood pressure systolic (mm Hg) & 31 & 113.35 & 8.64 & 33 & 120.88 & 12.58 & $0.007^{*}$ \\
\hline Blood pressure diastolic ( $\mathrm{mm} \mathrm{Hg}$ ) & 31 & 75.58 & 8.23 & 33 & 80.55 & 10.07 & $0.035 *$ \\
\hline Weight (kg) & 31 & 68.57 & 10.72 & 33 & 81.04 & 18.68 & $0.002 *$ \\
\hline Height (m) & 31 & 1.70 & 0.06 & 33 & 1.66 & 0.06 & 0.038 * \\
\hline BMI $\left(\mathrm{kg} / \mathrm{m}^{2}\right)$ & 31 & 23.81 & 3.16 & 33 & 29.18 & 6.13 & $<0.001$ * \\
\hline Number of tender points & 31 & 0.32 & 0.87 & 33 & 16.48 & 2.66 & $<0.001 *$ \\
\hline Mean PPT all sites $(\mathrm{kPa})$ & 31 & 383.66 & 109.91 & 33 & 132.55 & 84.66 & $<0.001 *$ \\
\hline PPT Trapezius catheter side $(\mathrm{kPa})$ & 31 & 303.74 & 103.01 & 33 & 109.54 & 69.01 & $<0.001$ * \\
\hline PPT Erector Spine catheter side $(\mathrm{kPa})$ & 31 & 432.61 & 147.15 & 33 & 121.79 & 87.91 & $<0.001$ * \\
\hline $\mathrm{MaxVO}_{2}$ per kg (mL/kg/min) & 30 & 2.64 & 0.49 & 30 & 2.17 & 0.53 & $0.001 *$ \\
\hline Grip force-max (N) & 30 & 311.59 & 51.58 & 33 & 240.38 & 63.94 & $<0.001 *$ \\
\hline Grip force-average (N) & 30 & 232.77 & 45.26 & 33 & 162.31 & 54.07 & $<0.001 *$ \\
\hline Grip force-endurance $(\mathrm{N})$ & 30 & 233.05 & 127.05 & 33 & 137.80 & 47.75 & $<0.001$ * \\
\hline TST & 30 & 17.80 & 3.03 & 32 & 13.63 & 3.47 & $<0.001$ * \\
\hline
\end{tabular}

\subsection{Microdialysis $(M D)$}

Pain intensity was significantly higher in FM throughout MD (Table 3), whereas CON had very low levels of pain. Mean blood flow (as well as blood flow at 140 and $160 \mathrm{~min}$ ) of the erector spinae was significantly lower in FM (Table 3); no significant differences were noted for the trapezius (Table 3). At baseline (140 min), both muscles had significantly higher pyruvate level in FM than in CON (Table 3). In addition, FM had significantly higher mean pyruvate of the trapezius than CON; a similar but non-significant trend was noted for erector spinae $(p=0.079)$. No significant group differences were found for both muscles regarding glucose, lactate, glycerol, and glutamate (Table 3). 
Table 3. Data obtained from the microdialysis of trapezius and erector spinae muscles.

\begin{tabular}{|c|c|c|c|c|c|c|c|}
\hline \multirow{2}{*}{$\begin{array}{c}\text { Groups } \\
\text { Variables }\end{array}$} & \multicolumn{2}{|c|}{ Controls } & \multicolumn{3}{|c|}{ FM } & \multicolumn{2}{|r|}{ Statistics } \\
\hline & $n$ & Mean & SD & $n$ & Mean & $\mathrm{SD}$ & $p$-value \\
\hline NRS pre insertion & 31 & 0.13 & 0.43 & 33 & 4.82 & 2.89 & $<0.001 *$ \\
\hline NRS $140 \mathrm{~min}$ & 31 & 0.42 & 0.85 & 33 & 5.55 & 2.21 & $<0.001 *$ \\
\hline NRS $160 \mathrm{~min}$ & 31 & 1.74 & 1.84 & 33 & 7.67 & 1.67 & $<0.001 *$ \\
\hline Difference NRS $160 \mathrm{~min}-140 \mathrm{~min}$ & 31 & 1.32 & 1.38 & 33 & 2.12 & 1.75 & 0.047 * \\
\hline Mean NRS $140-220 \mathrm{~min}$ & 31 & 0.61 & 0.84 & 33 & 6.07 & 1.85 & $<0.001 *$ \\
\hline Blood flow Trapezius $140 \mathrm{~min}$ & 30 & 0.68 & 0.07 & 32 & 0.65 & 0.07 & 0.054 \\
\hline Blood flow Trapezius $160 \mathrm{~min}$ & 30 & 0.70 & 0.10 & 32 & 0.67 & 0.11 & 0.249 \\
\hline Difference Blood flow Trapezius $160 \mathrm{~min}-140 \mathrm{~min}$ & 30 & 0.02 & 0.05 & 32 & 0.03 & 0.09 & 0.825 \\
\hline Mean Blood flow Trapezius 140-220 min & 30 & 0.69 & 0.07 & 32 & 0.66 & 0.07 & 0.107 \\
\hline Blood flow Erector spinae $140 \mathrm{~min}$ & 26 & 0.54 & 0.19 & 31 & 0.36 & 0.19 & $0.001 *$ \\
\hline Blood flow Erector spinae $160 \mathrm{~min}$ & 26 & 0.59 & 0.17 & 31 & 0.39 & 0.19 & $<0.001^{*}$ \\
\hline Difference Blood flow Erector spinae $160 \mathrm{~min}-140 \mathrm{~min}$ & 25 & 0.03 & 0.08 & 31 & 0.03 & 0.08 & 0.886 \\
\hline Mean Blood flow Erector spinae $140-220 \mathrm{~min}$ & 27 & 0.55 & 0.18 & 31 & 0.37 & 0.18 & $<0.001 *$ \\
\hline Glucose Trapezius $140 \mathrm{~min}\left(\mathrm{mmol} \mathrm{L}^{-1}\right)$ & 29 & 10.00 & 6.92 & 32 & 8.41 & 5.24 & 0.312 \\
\hline Glucose Trapezius $160 \mathrm{~min}\left(\mathrm{mmol} \mathrm{L}^{-1}\right)$ & 30 & 13.25 & 19.05 & 32 & 7.89 & 5.44 & 0.132 \\
\hline Difference Glucose Trapezius $160 \mathrm{~min}-140 \mathrm{~min}\left(\mathrm{mmolLl}^{-1}\right)$ & 29 & 3.11 & 19.08 & 32 & -0.52 & 4.94 & 0.303 \\
\hline Mean Glucose Trapezius $140-220 \mathrm{~min}\left(\mathrm{mmol} \mathrm{L}^{-1}\right)$ & 30 & 9.65 & 5.94 & 32 & 8.27 & 4.39 & 0.300 \\
\hline Glucose Erector spinae $140 \mathrm{~min}\left(\mathrm{mmol} \mathrm{L}^{-1}\right)$ & 24 & 8.35 & 6.32 & 31 & 9.12 & 6.33 & 0.657 \\
\hline Glucose Erector spinae $160 \mathrm{~min}\left(\mathrm{mmol} \mathrm{L}^{-1}\right)$ & 24 & 12.89 & 21.88 & 31 & 12.57 & 26.87 & 0.962 \\
\hline Difference Glucose Erector spinae $160 \mathrm{~min}-140 \mathrm{~min}\left(\mathrm{mmol} \mathrm{L}^{-1}\right)$ & 23 & 4.91 & 22.89 & 31 & 3.45 & 28.59 & 0.841 \\
\hline Mean Glucose Erector spinae $140-220 \mathrm{~min}\left(\mathrm{mmol} \mathrm{Lv}{ }^{1}\right)$ & 25 & 9.48 & 6.34 & 31 & 10.55 & 8.81 & 0.613 \\
\hline Lactate Trapezius $140 \mathrm{~min}\left(\mathrm{mmol} \mathrm{L}^{-1}\right)$ & 28 & 2.55 & 1.62 & 32 & 2.71 & 1.67 & 0.709 \\
\hline Lactate Trapezius $160 \mathrm{~min}\left(\mathrm{mmol} \mathrm{L}^{-1}\right)$ & 28 & 4.61 & 7.29 & 32 & 2.88 & 2.05 & 0.234 \\
\hline Difference Lactate Trapezius $160 \mathrm{~min}-140 \mathrm{~min}\left(\mathrm{mmol} \mathrm{L}^{-1}\right)$ & 27 & 2.19 & 6.80 & 32 & 0.17 & 1.90 & 0.145 \\
\hline Mean Lactate Trapezius $140-220 \mathrm{~min}\left(\mathrm{mmol} \mathrm{L}^{-1}\right)$ & 30 & 3.51 & 2.33 & 32 & 3.22 & 1.48 & 0.552 \\
\hline Lactate Erector spinae $140 \mathrm{~min}\left(\mathrm{mmol} \mathrm{L}^{-1}\right)$ & 23 & 1.86 & 1.04 & 29 & 2.68 & 3.80 & 0.275 \\
\hline Lactate Erector spinae $160 \mathrm{~min}\left(\mathrm{mmol} \mathrm{L}^{-1}\right)$ & 23 & 2.91 & 4.32 & 29 & 2.74 & 2.66 & 0.862 \\
\hline Difference Lactate Erector spinae $160 \mathrm{~min}-140 \mathrm{~min}\left(\mathrm{mmol} \mathrm{L}^{-1}\right)$ & 23 & 1.04 & 4.21 & 28 & 0.08 & 3.36 & 0.369 \\
\hline Mean Lactate Erector spinae $140-220 \mathrm{~min}\left(\mathrm{mmol} \mathrm{L}^{-1}\right)$ & 23 & 2.23 & 1.36 & 30 & 3.65 & 5.58 & 0.237 \\
\hline Pyruvate Trapezius $140 \mathrm{~min}(\mu \mathrm{mol} \mathrm{L}-1)$ & 30 & 12.97 & 10.98 & 32 & 27.96 & 18.19 & $<0.001 *$ \\
\hline Pyruvate Trapezius $160 \mathrm{~min}\left(\mu \mathrm{mol} \mathrm{L}^{-1}\right)$ & 30 & 25.54 & 34.47 & 32 & 33.84 & 31.16 & 0.323 \\
\hline Difference Pyruvate Trapezius $160 \mathrm{~min}-140 \mathrm{~min}(\mu \mathrm{mol} \mathrm{L}-1)$ & 30 & 12.57 & 31.74 & 32 & 5.88 & 24.81 & 0.357 \\
\hline Mean Pyruvate Trapezius $140-220 \mathrm{~min}\left(\mu \mathrm{mol} \mathrm{L}^{-1}\right)$ & 30 & 20.10 & 17.87 & 32 & 38.64 & 29.75 & $0.005 *$ \\
\hline Pyruvate Erector spinae $140 \mathrm{~min}(\mu \mathrm{mol} \mathrm{L}-1)$ & 25 & 12.37 & 10.97 & 31 & 26.59 & 30.74 & $0.032 *$ \\
\hline Pyruvate Erector spinae $160 \mathrm{~min}(\mu \mathrm{mol} \mathrm{L}-1)$ & 25 & 27.22 & 45.69 & 31 & 80.37 & 270.52 & 0.337 \\
\hline Difference Pyruvate Erector spinae $160 \mathrm{~min}-140 \mathrm{~min}\left(\mu \mathrm{mol} \mathrm{L}{ }^{-1}\right)$ & 24 & 14.66 & 46.09 & 31 & 53.79 & 275.61 & 0.495 \\
\hline Mean Pyruvate Erector spinae $140-220 \mathrm{~min}(\mu \mathrm{mol} \mathrm{L}-1)$ & 26 & 18.57 & 15.97 & 31 & 44.15 & 71.35 & 0.079 \\
\hline Glycerol Trapezius $140 \mathrm{~min}\left(\mathrm{mmol} \mathrm{L}^{-1}\right)$ & 30 & 90.37 & 60.04 & 32 & 95.26 & 52.10 & 0.733 \\
\hline Glycerol Trapezius $160 \mathrm{~min}\left(\mathrm{mmol} \mathrm{L}^{-1}\right)$ & 29 & 108.94 & 82.71 & 32 & 105.91 & 85.78 & 0.889 \\
\hline Difference Glycerol Trapezius $160 \mathrm{~min}-140 \mathrm{~min}\left(\mathrm{mmol} \mathrm{L}^{-1}\right)$ & 29 & 19.35 & 92.43 & 32 & 10.65 & 72.58 & 0.683 \\
\hline Mean Glycerol Trapezius $140-220 \mathrm{~min}\left(\mathrm{mmol} \mathrm{L}^{-1}\right)$ & 30 & 90.06 & 41.68 & 32 & 103.28 & 57.53 & 0.307 \\
\hline Glycerol Erector spinae $140 \mathrm{~min}\left(\mathrm{mmol} \mathrm{L}^{-1}\right)$ & 25 & 138.79 & 96.15 & 31 & 149.73 & 119.08 & 0.712 \\
\hline Glycerol Erector spinae $160 \mathrm{~min}\left(\mathrm{mmol} \mathrm{L}^{-1}\right)$ & 25 & 141.55 & 177.53 & 29 & 136.95 & 101.51 & 0.906 \\
\hline Difference Glycerol Erector spinae $160 \mathrm{~min}-140 \mathrm{~min}\left(\mathrm{mmol} \mathrm{L}^{-1}\right)$ & 24 & 7.17 & 198.28 & 29 & -10.62 & 97.96 & 0.673 \\
\hline Mean Glycerol Erector spinae $140-220 \mathrm{~min}\left(\mathrm{mmol} \mathrm{L}^{-1}\right)$ & 26 & 126.60 & 65.65 & 31 & 150.91 & 90.05 & 0.258 \\
\hline Glutamate Trapezius $140 \mathrm{~min}\left(\mathrm{mmol} \mathrm{L}^{-1}\right)$ & 30 & 49.77 & 31.65 & 32 & 56.06 & 32.50 & 0.444 \\
\hline Glutamate Trapezius $160 \mathrm{~min}\left(\mathrm{mmol} \mathrm{L}^{-1}\right)$ & 29 & 81.88 & 56.69 & 32 & 79.47 & 55.15 & 0.867 \\
\hline Difference Glutamate Trapezius $160 \mathrm{~min}-140 \mathrm{~min}\left(\mathrm{mmol} \mathrm{L}^{-1}\right)$ & 29 & 32.56 & 57.77 & 32 & 23.42 & 40.17 & 0.473 \\
\hline Mean Glutamate Trapezius $140-220 \mathrm{~min}\left(\mathrm{mmol} \mathrm{L}^{-1}\right)$ & 30 & 63.24 & 30.87 & 32 & 67.55 & 34.33 & 0.606 \\
\hline Glutamate Erector spinae $140 \mathrm{~min}\left(\mathrm{mmol} \mathrm{L}^{-1}\right)$ & 25 & 41.40 & 26.52 & 31 & 30.20 & 43.02 & 0.260 \\
\hline Glutamate Erector spinae $160 \mathrm{~min}\left(\mathrm{mmol} \mathrm{L}^{-1}\right)$ & 25 & 48.96 & 78.95 & 31 & 41.44 & 88.96 & 0.742 \\
\hline Difference Glutamate Erector spinae $160 \mathrm{~min}-140 \mathrm{~min}\left(\mathrm{mmol} \mathrm{L}^{-1}\right)$ & 24 & 6.21 & 79.89 & 31 & 11.24 & 88.62 & 0.828 \\
\hline Mean Glutamate Erector spinae $140-220 \mathrm{~min}\left(\mathrm{mmol} \mathrm{L}^{-1}\right)$ & 26 & 41.79 & 26.23 & 31 & 33.82 & 39.23 & 0.381 \\
\hline
\end{tabular}

NRS = Numeric rating scale for pain intensity. ${ }^{*}$ denotes statistical significance.

\subsection{Spectroscopy $\left.{ }^{31} P-M R S\right)$}

Significantly lower absolute concentrations of ATP and PCr were found in FM, but concentrations of $\mathrm{Pi}$ and $\mathrm{pH}$ showed no significant group differences (Table 4). In $\mathrm{FM}, \mathrm{PCr} / \mathrm{P}_{\text {tot }}$ was significantly lower and $\mathrm{Pi} / \mathrm{PCr}$ was significantly higher; the other ratios did not differ (Table 4). 
Table 4. Results obtained from spectroscopy examination of the erector spinae muscle.

\begin{tabular}{cccccccc}
\hline Group & CON & \multicolumn{3}{c}{ FM } & & Statistics \\
\hline Variables & $n$ & Mean & SD & $n$ & Mean & SD & $p$-value \\
\hline $\mathrm{PCr}(\mathrm{mM})$ & 30 & 40.06 & 8.54 & 32 & 34.07 & 11.49 & $0.024^{*}$ \\
$\mathrm{Pi}(\mathrm{mM})$ & 30 & 5.68 & 1.84 & 32 & 5.29 & 1.76 & 0.409 \\
$\mathrm{ATP}(\mathrm{mM})$ & 30 & 8.64 & 1.49 & 32 & 7.57 & 1.91 & $0.017^{*}$ \\
$\mathrm{pH}$ & 30 & 7.03 & 0.03 & 32 & 7.03 & 0.03 & 0.514 \\
Ratio ATP/P tot & 30 & 0.30 & 0.02 & 32 & 0.30 & 0.02 & 0.897 \\
Ratio PCr/P tot & 30 & 1.37 & 0.06 & 32 & 1.30 & 0.13 & $0.018^{*}$ \\
Ratio Pi/Ptot & 30 & 0.19 & 0.03 & 32 & 0.20 & 0.03 & 0.098 \\
Ratio ATP/PCr & 30 & 0.22 & 0.02 & 32 & 0.23 & 0.04 & 0.101 \\
Ratio Pi/PCr & 30 & 0.14 & 0.03 & 32 & 0.16 & 0.04 & $0.017^{*}$ \\
\hline
\end{tabular}

$\mathrm{CON}$ = controls; $\mathrm{FM}$ = fibromyalgia; $\mathrm{SD}$ = standard deviation; $\mathrm{PCr}$ = phosphocreatine; $\mathrm{Pi}$ = inorganic Phosphate; $\mathrm{P}_{\text {tot }}=$ total phosphorus; ATP $=$ adenosine triphosphate. ${ }^{*}$ denotes statistical significance.

\subsection{Regression Analyses}

The regression analyses investigated whether it was possible to regress group membership (FM or CON), pain intensity and PPT variables, blood flow in the erector spinae, and physical tests using the variables shown in Tables 3 and 4 (except the pain intensity variables from the MD (Table 3)).

\subsubsection{Group Membership}

In the multivariate context, blood flow aspects of the erector spinae together with PCr, ATP, and two spectroscopy ratios $\left(\mathrm{PCr} / \mathrm{P}_{\text {tot }}\right.$ and $\left.\mathrm{Pi} / \mathrm{PCr}\right)$ were significant regressors of the group differentiation (FM vs. CON) (Table 5). In addition, group differentiation was significantly influenced by pyruvate levels and blood flow of the trapezius.

Table 5. OPLS-DA of group membership (CON denoted 0 and FM denoted 1). Regressors used data from spectroscopy and microdialysis (except pain variables from microdialysis) (cf. Tables 3 and 4). The regression had one predictive component. Only significant variables are shown (i.e., variables with VIP $>1.0$ and absolute $\mathrm{p}(\mathrm{corr}) \geq 0.50)$.

\begin{tabular}{ccc}
\hline Variables & VIP & p(corr) \\
\hline Blood flow Erector spinae $140 \mathrm{~min}$ & 2.37 & -0.83 \\
Mean Blood flow Erector spinae 140-220 min & 2.27 & -0.81 \\
Blood flow Erector spinae 160 min & 2.23 & -0.80 \\
PCR (mM) & 1.97 & -0.70 \\
PCr/P tot & 1.94 & -0.69 \\
ATP (mainly ATP; mM) & 1.94 & -0.69 \\
Pi/PCr & 1.82 & 0.65 \\
Pyruvate trapezius 140 min & 1.60 & 0.57 \\
Mean Blood flow Trapezius 140-220 min & 1.57 & -0.55 \\
ATP/PCr & 1.49 & 0.53 \\
Blood flow Trapezius 160 min & 1.42 & -0.50 \\
\hline $\mathrm{R}^{2}$ & 0.26 & \\
$\mathrm{Q}^{2}$ & 0.18 & \\
CV-ANOVA $p$-value & 0.003 & \\
\hline
\end{tabular}

VIP and p(corr) are reported for each regressor (i.e., the loading of each variable scaled as a correlation coefficient and therefore standardizing the range from -1 to +1 ). The sign of $\mathrm{p}$ (corr) indicates the direction of the correlation with the dependent variable $(+=$ positive correlation; $-=$ negative correlation). Hence, a negative $p($ corr $)$ indicates lower values for a certain variable in FM in the multivariate context. The four bottom rows report $\mathrm{R}^{2}, \mathrm{Q}^{2}, P$-value of the CV-ANOVA, and number of subjects included in the regression $(n)$ from the second OPLS regression (see Statistics for details). 


\subsubsection{Pain Intensity in FM}

Three spectroscopy ratios ( $\mathrm{Pi} / \mathrm{PCr}$ positively, $\mathrm{Pi} / \mathrm{P}_{\text {tot }}$ positively, and $\mathrm{PCr} / \mathrm{P}_{\text {tot }}$ negatively) as well as blood flow aspects of both muscles (negatively) were in the multivariate context strongest associated with pain intensity (Table 6). Additionally, pyruvate levels of erector spinae contributed to the variations in pain intensity. More than $50 \%$ of the variation (i.e. $\mathrm{R}^{2}=0.52$ ) in pain intensity was explained of the variables displayed in Table 6.

Table 6. OPLS of global pain intensity previous seven days in FM. Regressors used data from spectroscopy and microdialysis (except pain variables from microdialysis) (cf. Tables 3 and 4). The regression had one predictive component. Only significant variables are shown (i.e., variables with VIP $>1.0$ and absolute $\mathrm{p}($ corr $) \geq 0.50)$.

\begin{tabular}{ccc}
\hline Variables & VIP & p(corr) \\
\hline Pi/PCr & 1.71 & 0.65 \\
Mean Blood flow Trapezius 140-220 min & 1.70 & -0.64 \\
Glutamate Trapezius 160 min & 1.53 & -0.57 \\
Blood flow Trapezius 140 min & 1.52 & -0.57 \\
Blood flow Erector spinae 140 min & 1.51 & -0.57 \\
Pi/P tot & 1.51 & 0.57 \\
PCr/P tot & 1.51 & -0.57 \\
Difference Pyruvate Erector spinae 160 min-140 min & 1.48 & 0.56 \\
Pyruvate Erector spinae 160 min & 1.48 & 0.56 \\
Blood flow Trapezius 160 min & 1.48 & -0.55 \\
Difference Glutamate Erector spinae 160 min-140 min & 1.46 & 0.55 \\
Mean Pyruvate Erector spinae 140-220 min & 1.46 & 0.55 \\
Difference Glucose Erector spinae 160 min-140 min & 1.39 & 0.52 \\
PCr & 1.38 & -0.53 \\
Mean Blood flow Erector spinae 140-220 min & 1.37 & -0.51 \\
Blood flow Erector spinae 160 min & 1.35 & -0.51 \\
\hline $\mathrm{R}^{2}$ & 0.52 & \\
$\mathrm{Q}^{2}$ & 0.32 & \\
\hline CV-ANOVA $p$-value & 0.006 & \\
\hline
\end{tabular}

VIP and p(corr) are reported for each regressor (i.e., the loading of each variable scaled as a correlation coefficient and therefore standardizing the range from -1 to +1$)$. The sign of $\mathrm{p}(\mathrm{corr})$ indicates the direction of the correlation with the dependent variable $(+=$ positive correlation; $-=$ negative correlation). Hence, a positive $p$ (corr) for a certain variable indicates a positive correlation with pain intensity in FM in the multivariate context. The four bottom rows report $\mathrm{R}^{2}, \mathrm{Q}^{2}, P$-value of the CV-ANOVA, and number of subjects included in the regression $(n)$ from the second OPLS regression (see Statistics for details).

\subsubsection{Pressure Pain Thresholds (PPT) for Trapezius and Erector Spinae}

Since FM and CON differed markedly in PPTs (Table 2), an OPLS regression of all subjects will mainly reflect the group differentiation (cf. Table 5). The regressions were made separately in each group. The OPLS of PPT over erector spinae included both spectroscopy and MD data while the analysis of PPT over the trapezius used MD data since spectroscopy not was done for this muscle.

It was not possible to significantly regress PPT in CON in either of the two muscles.

\section{PPT of trapezius}

In FM, increases in glutamate, lactate, glycerol, and pyruvate from $140 \mathrm{~min}$ to $160 \mathrm{~min}$ correlated positively with PPT (Table 7). Glutamate level at $160 \mathrm{~min}$ and blood flow aspects of trapezius also contributed and correlated positively with PPT. 
Table 7. OPLS of PPT over trapezius in FM. Regressors used data from microdialysis of this muscle (except pain variables from microdialysis) (cf. Table 3). Only significant variables are shown (i.e., the variables with VIP $>1.0$ and absolute $\mathrm{p}(\mathrm{corr}) \geq 0.50$ ).

\begin{tabular}{ccc}
\hline Variables & VIP & p(corr) \\
\hline Difference Glutamate Trapezius 160 min-140 min & 1.84 & 0.78 \\
Difference Lactate Trapezius 160 min-140 min & 1.71 & 0.72 \\
Glutamate Trapezius 160 min & 1.51 & 0.64 \\
Blood flow Trapezius 140 min & 1.41 & 0.60 \\
Difference Glycerol Trapezius 160 min-140 min & 1.39 & 0.59 \\
Mean Blood flow Trapezius 140-220 min & 1.36 & 0.57 \\
Difference Pyruvate Trapezius 160 min-140 min & 1.20 & 0.51 \\
\hline $\mathrm{R}^{2}$ & 0.32 & \\
$\mathrm{Q}^{2}$ & 0.19 & \\
CV-ANOVA P-value & 0.050 & \\
$n$
\end{tabular}

VIP and p(corr) are reported for each regressor (i.e., the loading of each variable scaled as a correlation coefficient and therefore standardizing the range from -1 to +1$)$. The sign of $p($ corr $)$ indicates the direction of the correlation with the dependent variable $(+=$ positive correlation; $-=$ negative correlation). Hence, a positive $\mathrm{p}$ (corr) for a certain variable indicates a positive correlation with PPT over trapezius in FM in the multivariate context. The four bottom rows report $\mathrm{R}^{2}, \mathrm{Q}^{2}$, P-value of the CV-ANOVA, and number of subjects included in the regression $(n)$ from the OPLS regression (see Statistics for details).

\section{PPT of Erector spinae}

In FM Pi/PCr, Pi/P tot, two glycerol aspects and pyruvate at 140 min were the most important regressors of PPT (Table 8$)$.

Table 8. OPLS of PPT over erector spinae in FM. Regressors used data from microdialysis and spectroscopy of this muscle (except pain variables from microdialysis) (cf. Tables 3 and 4 ). The regression had one predictive component. Only significant variables are shown (i.e., variables with VIP > 1.0 and absolute $\mathrm{p}($ corr $) \geq 0.50)$.

\begin{tabular}{ccc}
\hline Variables & VIP & p(corr) \\
\hline $\mathrm{Pi} / \mathrm{PCr}$ & 1.73 & -0.69 \\
$\mathrm{Pi} / \mathrm{P}_{\text {tot }}$ & 1.58 & -0.63 \\
Mean Glycerol Erector spinae $140-220 \mathrm{~min}$ & 1.52 & -0.60 \\
Glycerol Erector spinae $140 \mathrm{~min}$ & 1.51 & -0.60 \\
Pyruvate Erector spinae $140 \mathrm{~min}$ & 1.46 & -0.58 \\
Difference Blood flow Erector spinae $160 \mathrm{~min}-140 \mathrm{~min}$ & 1.44 & -0.57 \\
Blood flow Erector spinae $140 \mathrm{~min}$ & 1.41 & 0.56 \\
Lactate Erector spinae $140 \mathrm{~min}$ & 1.38 & -0.54 \\
$\mathrm{PCr} / \mathrm{P}_{\text {tot }}$ & 1.36 & 0.54 \\
$\mathrm{R}^{2}$ & 0.32 & \\
$\mathrm{Q}^{2}$ & 0.24 & \\
\hline $\mathrm{CV}-\mathrm{ANOVA} P$-value & 0.020 &
\end{tabular}

$\mathrm{VIP}$ and $\mathrm{p}$ (corr) are reported for each regressor (i.e., the loading of each variable scaled as a correlation coefficient and therefore standardizing the range from -1 to +1 ). The sign of $p($ corr) indicates the direction of the correlation with the dependent variable $(+=$ positive correlation; $-=$ negative correlation). Hence, a positive $p$ (corr) for a certain variable indicates a positive correlation with PPT of erector spinae in FM in the multivariate context. The four bottom rows report $\mathrm{R}^{2}, \mathrm{Q}^{2}, P$-value of the CV-ANOVA, and number of subjects included in the regression $(n)$ from the OPLS regression (see Statistics for details).

\subsubsection{Blood Flow in Erector Spinae}

In this analysis, spectroscopy data and baseline MD data were used as regressors of blood flow at baseline for erector spinae. We obtained significant regressions for all subjects taken together and, in each group, separately (Table 9). Five significant regressors were obtained for each regression and 
four of these were the same although with different relative importance within each regression: ATP (positively correlated); $\mathrm{Pi} / \mathrm{PCr}$ (negatively), $\mathrm{Pi} / \mathrm{P}$ tot (negatively); and $\mathrm{PCr} / \mathrm{Ptot}$ (positively). In all subjects and in FM, but not in CON, PCr was a significant regressor of blood flow.

Table 9. OPLS regressions of blood flow at baseline $(140 \mathrm{~min})$ in erector spinae in all subjects taken together, in CON, and in FM. Regressors used data from spectroscopy and MD data from baseline of this muscle (except pain variables from microdialysis). Only significant variables are shown (i.e., variables with VIP > 1.0 and absolute $p($ corr $) \geq 0.50)$.

\begin{tabular}{|c|c|c|c|c|c|c|c|c|}
\hline All & & & $\mathrm{CON}$ & & & FM & & \\
\hline Variables & VIP & $\mathrm{p}$ (corr) & Variables & VIP & $\mathrm{p}$ (corr) & Variables & VIP & $\mathrm{p}$ (corr) \\
\hline ATP & 1.63 & 0.71 & $\mathrm{Pi} / \mathrm{PCr}$ & 1.53 & -0.68 & $\mathrm{Pi} / \mathrm{PCr}$ & 1.87 & -0.86 \\
\hline $\mathrm{Pi} / \mathrm{PCr}$ & 1.62 & -0.71 & ATP & 1.42 & 0.64 & $\mathrm{Pi} / \mathrm{P}_{\text {tot }}$ & 1.69 & -0.78 \\
\hline $\mathrm{Pi} / \mathrm{P}_{\text {tot }}$ & 1.45 & -0.64 & $\begin{array}{l}\text { Glycerol Erector spinae } 140 \\
\text { min }\end{array}$ & 1.39 & -0.63 & $\mathrm{PCr} / \mathrm{P}_{\text {tot }}$ & 1.68 & 0.78 \\
\hline PCR & 1.43 & 0.62 & $\mathrm{Pi} / \mathrm{P}_{\text {tot }}$ & 1.37 & -0.61 & PCR & 1.17 & 0.54 \\
\hline $\mathrm{PCr} / \mathrm{P}_{\text {tot }}$ & 1.42 & 0.62 & $\mathrm{PCr} / \mathrm{P}_{\text {tot }}$ & 1.20 & 0.54 & ATP & 1.14 & 0.52 \\
\hline $\mathrm{R}^{2}$ & 0.50 & & $R^{2}$ & 0.56 & & $R^{2}$ & 0.37 & \\
\hline $\mathrm{Q}^{2}$ & 0.45 & & $Q^{2}$ & 0.47 & & $Q^{2}$ & 0.25 & \\
\hline $\begin{array}{l}\text { CV-ANOVA } \\
p \text {-value }\end{array}$ & $<0.001$ & & CV-ANOVA $P$-value & $<0.001$ & & $\begin{array}{l}\text { CV-ANOVA } \\
P \text {-value }\end{array}$ & 0.022 & \\
\hline$n$ & 55 & & $n$ & 25 & & $n$ & 30 & \\
\hline
\end{tabular}

VIP and $\mathrm{p}$ (corr) are reported for each regressor (i.e., the loading of each variable scaled as a correlation coefficient and therefore standardizing the range from -1 to +1$)$. The sign of $\mathrm{p}(\mathrm{corr})$ indicates the direction of the correlation with the dependent variable $(+=$ positive correlation; $-=$ negative correlation). Hence, a positive $p$ (corr) for a certain variable indicates a positive correlation with blood flow of erector spinae in the multivariate context. The four bottom rows of each regression report $\mathrm{R}^{2}, \mathrm{Q}^{2}, P$-value of the $\mathrm{CV}$-ANOVA, and number of subjects included in the regression (n) from the OPLS regression (see Statistics for details).

\subsubsection{Physical Tests}

Grip strength aspects: It was impossible to obtain significant regressions in the groups separately. In all subjects (i.e., as a group), the strongest associations with grip strength were pyruvate variables from both muscles (negatively) and blood flow of thee erector spinae (positively) (Table S1).

Lower extremity muscle performance (TST): In all subjects (i.e., as a group), the strongest associations with TST were $\mathrm{Pi} / \mathrm{PCr}$ and $\mathrm{Pi} / \mathrm{P}_{\text {tot }}$ (both negatively), mean pyruvate levels of the two muscles (negatively), and baseline blood flow of erector spinae (positively) (Table S2). In FM, the strongest regressors in the significant regression of TST were pyruvate, glutamate, and glucose aspects (all negatively) (Table S3). In CON, no significant regressions of TST were obtained.

Aerobic fitness: No significant regressions for aerobic fitness were obtained for all subjects (as a group) or the CON. In FM, however, aerobic fitness showed the strongest associations with glycerol aspects (negatively and positively), pyruvate (negatively), and lactate (negatively) levels in the trapezius and to some extent the erector spinae (Table S4).

\section{Discussion}

(Original studies using other FM criteria than ACR 1990 criteria have been indicated.)

\subsection{Major Results}

FM was clearly associated with higher levels of pyruvate and lower levels of ATP and PCr, a finding that suggests muscle mitochondrial dysfunctions in FM. The multivariate analysis of the groups (FM vs. CON) (Table 5) showed that blood flow of the erector spine together with the spectroscopy variables $\mathrm{PCR}, \mathrm{ATP}, \mathrm{PCr} / \mathrm{P}_{\text {tot }}$, and $\mathrm{Pi} / \mathrm{PCr}$ were more important for group differentiation than the other variables that exhibited significant group differences. The multivariate associations between metabolic variables and pain aspects (intensity and PPTs) indicated that peripheral factors contribute to the perception of pain in FM. 


\subsection{Significantly Higher Levels of Pyruvate in FM}

The breakdown of glucose and glycogen in the cytosol results in pyruvate and lactate. Increased pyruvate was found in both muscles of FM, a finding that agrees with two other MD studies of trapezius that reported increased levels of pyruvate and/or lactate $[9,10]$. Both substances were also significantly increased in the vastus lateralis in a third FM cohort [11]. Based on the three muscles studied in these four FM cohorts, FM seems to be associated with increases in key products of glycolysis (i.e., pyruvate and possibly lactate). The increased pyruvate level in the trapezius cannot be explained by insufficient oxygen supply as no blood flow alteration was found in this cohort or in the two other FM cohorts $[10,11]$. In addition, the analyses of blood flow in the erector spinae supports this interpretation as no association with pyruvate levels exists (Table 9).

The mitochondrial pyruvate carrier (MPC) is responsible for the transportation of pyruvate into mitochondria and its use in the production of ATP [7]. Pyruvate can be reduced to lactate and vice versa in the cytosol by the bi-directional enzyme lactate dehydrogenase (LDH) $[7,56]$. Challenging traditional views regarding glycolysis, it is now evident that lactate is produced both during anaerobic and aerobic conditions and can be metabolized in the same cell or transported to other cells via lactate shuttles $[57,58]$. Under aerobic conditions, glycolysis produces lactate, which muscle mitochondria use to produce ATP $[57,58]$. Lactate is transported via monocarboxylate transporters into the mitochondrion and converted to pyruvate. This pyruvate, via pyruvate dehydrogenase, is converted into Acetyl-CoA before it enters the tricarboxylic acid cycle (TCA) and ultimately contributes to oxidative phosphorylation (OXPHOS) and the electron transport chain (ECT), and therefore the production of ATP [57-60].

\subsection{Lower Absolute Concentrations of PCr and ATP of Erector Spinae in FM}

ATP is critical for muscle contractile activity and the demand can increase more than 100-fold during work [61,62]. To provide energy for muscular contraction, ATP splits into ADP, $\mathrm{Pi}$, and $\mathrm{H}^{+}$ ions by ATPase enzyme [63]. PCr acts as an intermediate energy buffer and "shuttles" energy-rich phosphate present in ATP from the mitochondria to the myofibrils [64]. As intramuscular stores of ATP are small, free fatty acids and glucose/glycogen pathways are also activated to produce ATP [62]. Two earlier studies of FM determined the absolute concentrations of PCr and ATP [14,15] and both found significantly lower levels of these in the quadriceps muscle. These results were confirmed for the erector spinae in this study (Table 4). Lower ATP levels seem to characterize FM as low ATP levels have also been found in skin, plasma, platelets, neuronal cells, and peripheral blood mononuclear cells of FM patients [65-67]. The decreased ATP and PCr levels were parallel in FM as the ATP/PCr ratio was not different between the two groups (Table 4). This finding agrees with the two earlier ${ }^{31} \mathrm{P}-\mathrm{MRS}$ studies based on our calculations of their data $[14,15]$. The ratios involving $\mathrm{PCr}$ and phosphorus (i.e., $\mathrm{PCr} / \mathrm{P}_{\text {tot }}$ and $\mathrm{Pi} / \mathrm{PCr}$ ) both showed significant group differences, which is mainly due to the significantly lower $\mathrm{PCr}$ in $\mathrm{FM}$ as the concentration of $\mathrm{Pi}$ and the $\mathrm{Pi} / \mathrm{P}_{\text {tot }}$ did not differ (Table 4). Hence, these two ratios indicate alterations in the PCr-phosphorus balance. The lower ATP production in FM subsequently results in lower PCr concentration, whereas the $\mathrm{P}_{\mathrm{i}}$ concentration is not affected and therefore the $\mathrm{P}_{\mathrm{i}} / \mathrm{PCr}$ ratio increased in FM, ultimately decreasing $\mathrm{PCr} / \mathrm{P}_{\text {tot }}$ (Table 4). It was evident that these two ratios were also important for pain aspects and blood flow.

\subsection{What is the Explanation for Metabolic and Blood Flow Alterations?}

Mitochondrial dysfunction could explain the increased pyruvate levels and lower absolute concentrations of ATP and PCr in FM. The aerobic capacity of muscles is largely governed by the number of mitochondria and their enzymes [68]. Mitochondria are highly dynamic organelles and a proper balance between fusion and fission of mitochondria is important for integrity and function including reactive oxygen species (ROS) generation, apoptosis regulation, and energy metabolism $[8,69,70]$. Our explanation agrees with previous FM studies that found trapezius muscle fibers had mitochondrial alterations [71,72]. Moreover, different muscle alterations have been reported for quadriceps [73-75]. 
Mitochondrial alterations are not specific for FM and have also been found in muscles that exhibit localized chronic pain [76,77]. Mitochondrial conditions are divided into primary and secondary mitochondrial diseases [78]. The latter-possibly present in FM—can be acquired secondary to adverse environmental effects that result in oxidative stress. Peripheral metabolic alterations have also been observed in other FM studies. A proteomic study of the trapezius muscle of FM found significant alterations in metabolic proteins involved in ATP production and in glycolysis and glucogenesis such as lower concentrations of creatine kinase, a situation that could contribute to lower concentrations of PCr [79]. In addition, plasma metabolomic studies have found that FM differed from healthy subjects in energy, lipid, and amino acid metabolites [80]. Altered metabolic profile in urine has also been reported in patients with FM $[81,82]$. Larger prospective studies of other peripheral molecules suggest that FM is associated with peripheral biochemical alterations in muscle and in plasma [83-89] (Han et al. used ACR 2010 criteria).

The increased pyruvate levels may reflect insufficient transportation of pyruvate into the mitochondria or insufficient reduction of pyruvate to lactate and/or insufficient transport of lactate into the mitochondria. Both these conditions would result in a decrease of ATP and PCr. In addition, increased pyruvate levels may be the result of an inflammatory environment that switches metabolism from OXPHOS to glycolysis, a condition that would prevent pyruvate from being transported into mitochondria. In this scenario, LDH in the cytosol converts two pyruvate molecules back into lactate, resulting in only two ATP molecules rather than the 36 molecules generated by OXPHOS [90], a decrease in energy production.

Significant associations were found mainly between the spectroscopy variables and blood flow in the erector spinae at baseline (Table 9). As in other studies, we found that blood flow was positively associated with ATP; intraluminal ATP is a vasodilator that can lead to both activation of vasoactive substances (e.g., nitric oxide, NO) and prostacyclin by activation of inwardly rectifying potassium channels [91]. Moreover, PCr concentration and the balance between $\mathrm{PCr}$ and phosphorus were multivariately associated with blood flow (Table 9). At this time, causality is unclear and cannot be determined in this study. In addition, other factors such as increased sympathetic tone may contribute to lower blood flow in FM [92]. The unaltered blood flow in trapezius muscle agrees with earlier studies of this muscle in FM $[10,11]$. A conflicting situation exists regarding muscle blood flow in FM [93]. The different situations in the two muscles may indicate that FM muscles have different predilections for blood flow changes and/or temporal aspects (i.e., the pain condition is first initiated in the neck-shoulder muscles).

\subsection{What Is the Reason for Mitochondrial Dysfunction?}

The observation of reduced physical capacity in FM (Table 2) agrees with other studies [94,95] (Umay et al. used ACR 2013 criteria). The mitochondrial density and capacity increases as the result of exercise $[69,70]$. Aging, immobilization, and long-term physical inactivity are associated with negative changes in content and function of mitochondria $[95,96]$. Muscle disuse/inactivity causes large loss in muscle mass that is preceded by changes in mitochondrial content [70]. According to reviews, aerobic and muscle strengthening exercise interventions reduce pain and improve general well-being in patients with FM $[97,98]$. Exercise is associated with upregulations of mitochondrial protein synthesis and therefore the capacity for ATP generation, oxygen delivery, and antioxidant capacity [99]. It is not known if such effects will also be achieved in FM and if they are associated with improvements in the clinical presentation. An exercise intervention of FM found that increased pyruvate levels in vastus lateralis were normalized after a 16-week exercise intervention [11]. Therefore, at least some metabolic alterations in FM can be addressed successfully using exercise. Mitochondrial function has also been linked to insulin sensitivity: individuals whose ATP production increased as a result of exercise also had enhanced insulin sensitivity [100]. FM had higher BMI than CON (Table 2). Furthermore, physical exercise had fewer positive effects on mitochondrial function in obese subjects than in lean subjects [100]. Deconditioning is associated with high sympathetic tone and low para-sympathetic 
tone [92]. Muscle strength interventions may reduce sympathetic hyperactivity and abnormal vagal balance [94].

However, mitochondrial disturbances may not be directly linked to physical activity level. Mitochondrial dysfunction in the skin may indicate that factors-possibly interacting with each other-other than inactivity are responsible $[65,66]$. Aging and obesity are both associated with mitochondrial dysfunction $[76,96]$. Partly in agreement with these observations, we found that aside from group (FM or CON), BMI-but not age-was a significant regressor of PCr, ATP, and puruvate of trapezius according to OPLS regressions. FM had more insomnia than CON (Table 1); interestingly, bidirectional associations exist between circadian rhythms and mitochondrial activity [90]. In addition, common comorbidities in FM may be responsible; diabetes, cardiovascular disease, and neurogenerative disorders are associated with secondary mitochondrial dysfunctions [78]. Altered activation patterns of the FM muscle [101-104] may indicate muscular over-activity and therefore alterations in pyruvate and/or lactate levels $[105,106]$. Mitochondria dysfunction may also be linked to the pain per se as discussed below.

\subsection{Multivariate Associations between Pain Aspects and Spectroscopy and MD Variables}

High pain intensity is a considerable burden for patients with FM. At the group level, pain intensity was above six on the NRS (Table 1). Pain intensity correlated with the metabolic situation and blood flow aspects; $>50 \%$ of the variation in pain intensity was explained by these factors (Table 6 ). Specifically, $\mathrm{PCr} / \mathrm{P}_{\text {tot }}$ and $\mathrm{Pi} / \mathrm{PCr}$ together with blood flow aspects of both muscles, where the $\mathrm{Pi} / \mathrm{P}_{\text {tot }}$ and pyruvate aspects were important regressors of pain intensity (Table 6). A proteomic study of mainly patients with FM found that 12 muscle proteins showed strong multivariate associations with pain intensity [107]; proteins related to ATP synthesis were among the important proteins [107]. In addition, certain plasma proteins showed strong multivariate correlations with pain intensity in two cohorts of mainly FM [87,108]. In contrast, an inflammatory panel of 92 cytokines/chemokines from plasma were not correlated with pain intensity [109]. In the exercise intervention above-mentioned, the degree of normalization in pyruvate was significantly associated with decreases in pain intensity although the association was weak [11]. Thus, exercise interventions normalizing muscle metabolic situation may affect pain intensity.

As expected, the PPT registrations confirmed the presence of generalized hyperalgesia/allodynia in FM (Table 2) [110-113] (different criteria used in these references). PPT measures when an acute mechanical stimulus becomes painful; in healthy subjects, the stimuli activates both the peripheral nociceptors and the CNS. In FM, peripheral metabolism and blood flow alterations influenced PPT. It was not possible to regress PPT in CON because factors other than those in FM are important for PPT; such group differences were also found in a plasma proteomic study [114]. PPT over trapezius (spectroscopy not made) was positively associated with the differences in blood flow and in concentrations of glutamate, lactate, glycerol, and pyruvate (Table 7). Therefore, more prominent metabolic changes during highly repetitive work were associated with higher PPT in FM. Pi/PCr, $\mathrm{Pi} / \mathrm{P}_{\text {tot }}$, two glycerol aspects and pyruvate at $140 \mathrm{~min}$ were the most important regressors of PPT over erector spinae (Table 8). Associations between peripheral biochemical molecules and PPT in FM have been reported previously where muscle (including proteins related to ATP synthesis) and plasma proteins showed strong multivariate associations with PPT $[87,107,114]$. The acute pressure used to elicit PPT is a peripheral input, which in FM partly reflects the metabolic status in muscle tissue. As only approximately one-third of the variation in PPT was explained, other peripheral and/or central factors-not mutually exclusive — contribute in FM (e.g., a continuous nociceptive input, peripheral nociceptor sensitization, secondary hyperalgesia in the primary pain region, and a generalized state of hypersensitivity such as central sensitization including impaired descending control of nociception).

As chronic pain is common in patients with different mitochondrial diseases [115], it would be helpful to know whether metabolic alterations directly interact with nociception and pain in FM or whether these metabolic alterations reflect other mitochondrial mechanisms more directly associated 
with nociception and pain. For example, increased lactate and pyruvate levels can induce ROS, which in turn may interact with nociception [116-119]. However, we suggest that other aspects of dysfunctional mitochondria are responsible and interact with immune and nociceptive systems. Mitochondrial dysfunction can lead to inflammatory conditions [120]. Mitochondria have a vital role in the regulation of immune cells and contribute to immune responses [121]. Dysfunctional mitochondria release damage-associated molecular patterns recognized by the immune system (e.g., increased levels of mtROS or mtDNA) that trigger immune and inflammatory responses [90]. Normally, dysfunctional mitochondria that produce high mtROS are removed by mitophagy to avoid harmful inflammation effects [122]. Increased ROS levels have been reported in FM [123,124]. Excessive production of mtROS has been associated with aging, osteoarthritis, and rheumatoid arthritis [90]. Increased mtROS levels can activate inflammasomes (NLRP3) that stimulate caspase-1, which upregulates several inflammatory cytokines (e.g., IL-1 $\beta$ and IL-18) [120]. NLRP3 may be activated in FM [125]. IL-1 $\beta$ causes pain by directly acting on sensory neurons via their receptors [126] and stimulates production of additional algogenic substances [127]. A systematic review [128] was unable to confirm increased plasma levels of IL-1 $\beta$ (also in blood cells) and IL-18 in FM [125]. These conflicting results for IL-1 $\beta$ may be due to IL-1 $\beta$ 's anti-inflammatory and pro-inflammatory properties [129]. Mitochondria can also modulate innate immunity via nuclear factor kappa B (NF-кB) and interferon regulatory factor I pathways with subsequent activation of TNF- $\alpha$, IL-1, IL-6, IL-8, IFN $\beta$, and IFN $\lambda 1$ [8,90]. Other dysfunctions of mitochondria (e.g. calcium overload, increased apoptosis, decreased mitophagy, and oxidized mtDNA) can also activate inflammatory pathways [120,122].

\subsection{Strengths and Limitations}

We used the ACR 1990 classification criteria for FM to simplify comparisons with earlier studies. In future studies, both ACR 1990 and newer criteria should be used to optimize comparisons with other studies. During the study, the MR scanner software was upgraded, and the ${ }^{31} \mathrm{P}$-coil was replaced, changes that have the potential of introducing limitations. However, as we ensured that the FM and CON subjects were scanned intermittently, these changes are not likely to affect the outcome. In addition, there was no significant difference in the proportion of the subjects who were examined with different versions and coils (Supplementary data 1). Another strength is that we used multivariate techniques. Typically, FM studies are hypothesis-driven studies that focus on a few molecules. To achieve a mechanistic understanding of the biological factors maintaining pain conditions, it is necessary to understand the activated molecular mechanisms from a broader system biology perspective $[130,131]$, a conclusion that influenced how we analyzed the data. We combined traditional statistical methods with advanced multivariate methods to handle intercorrelated variables.

\section{Conclusions}

We found significant metabolic and blood flow alterations in the muscles of FM. The results may indicate muscle mitochondrial dysfunctions in FM. Although it is unclear why muscle mitochondrial dysfunctions are found in FM, inactivity, obesity, aging, and pain per se may be involved. The obtained significant regressions of pain intensity and PPT in FM agree with other studies that report significant multivariate associations between peripheral biological factors and pain aspects. We believe that our results may be important for understanding the pathophysiological mechanisms in FM and ultimately contribute to developing effective treatments for FM.

Supplementary Materials: The following are available online at http://www.mdpi.com/2077-0383/9/11/3527/s1, Figure S1: MRS Correction; Table S1: OPLS of the three grip strength variables (i.e., three simultaneous Y-variables) in all subjects taken together; Table S2: OPLS of TST in all subjects taken together; Table S3: OPLS of TST in FM; Table S4: OPLS of the aerobic fitness in FM. Supplementary data 1: MRS processing.

Author Contributions: Conceptualization, methodology, B.G. (Björn Gerdle), B.G. (Bijar Ghafouri), E.L., A.B., P.L., O.D.L, and M.F.F.; Software, B.G. (Bijar Ghafouri), O.D.L., and M.F.F.; Validation, B.G. (Bijar Ghafouri), O.D.L., and M.F.F.; Formal analysis, B.G. (Björn Gerdle), M.F.F., and O.D.L.; Investigation, B.G. (Björn Gerdle), B.G. (Bijar Ghafouri), A.B., P.L., and M.F.F.; Resources, B.G. (Björn Gerdle), B.G. (Bijar Ghafouri)., P.L., M.F.F.; 
and O.D.L.; data curation, B.G. (Björn Gerdle), and M.F.F.; Writing-original draft preparation, B.G. (Björn Gerdle) and M.F.F.; Writing—review and editing, B.G. (Björn Gerdle), B.G. (Bijar Ghafouri), E.L., A.B., P.L., H.v.E.-V., O.D.L., and M.F.F.; Visualization, B.G. (Björn Gerdle) and M.F.F.; Supervision, B.G. (Björn Gerdle); Project administration, B.G. (Björn Gerdle); Funding acquisition, B.G. (Björn Gerdle). All authors have read and agreed to the published version of the manuscript.

Funding: This research was funded by grants from the Swedish Research Council (grant number: 2018-02470) and County Council of Östergötland (Research-ALF; grant number: LIO-700931).

Acknowledgments: Research nurse Eva-Britt Lind and research physiotherapist Ulrika Wentzel Olausson are acknowledged for the data collection and support during the clinical examinations.

Conflicts of Interest: The authors declare no conflict of interest. The funders had no role in the design of the study; in the collection, analyses, or interpretation of data; in the writing of the manuscript, or in the decision to publish the results.

Data Availability Statement: The datasets generated and/or analyzed in this study are not publicly available as the Ethical Review Board has not approved the public availability of these data.

\section{References}

1. Albrecht, D.S.; Forsberg, A.; Sandstrom, A.; Bergan, C.; Kadetoff, D.; Protsenko, E.; Lampa, J.; Lee, Y.C.; Hoglund, C.O.; Catana, C.; et al. Brain glial activation in fibromyalgia-A multi-site positron emission tomography investigation. Brain Behav. Immun. 2019, 75, 72-83. [CrossRef] [PubMed]

2. Gerdle, B.; Larsson, B. Muscle. In Fibromyalgia Syndrome and Widespread Pain-From Construction to Relevant Recognition; Häuser, W., Perrot, S., Eds.; Wolters Kluwer: Philadelphia, PA, USA, 2018; pp. 215-231.

3. Jensen, K.B.; Kosek, E.; Petzke, F.; Carville, S.; Fransson, P.; Marcus, H.; Williams, S.C.R.; Choy, E.; Giesecke, T.; Mainguy, Y.; et al. Evidence of dysfunctional pain inhibition in Fibromyalgia reflected in rACC during provoked pain. PAIN 2009, 144, 95-100. [CrossRef] [PubMed]

4. Sluka, K.A.; Clauw, D.J. Neurobiology of fibromyalgia and chronic widespread pain. Neuroscience 2016, 338, 114-129. [CrossRef] [PubMed]

5. Üçeyler, N.; Sommer, C. Small nerve fiber pathology. In Fibromylagia Syndrome and Widespread Pain-From Construction to Relevant Recognition; Häuser, W., Perrot, S., Eds.; Wolters Kluwer: Philadelphia, PA, USA, 2018; pp. 204-214.

6. Frontera, W.R.; Ochala, J. Skeletal muscle: A brief review of structure and function. Calcif. Tissue Int. 2015, 96, 183-195. [CrossRef] [PubMed]

7. Bender, T.; Martinou, J.C. The mitochondrial pyruvate carrier in health and disease: To carry or not to carry? Biochim. Biophys. Acta 2016, 1863, 2436-2442. [CrossRef] [PubMed]

8. Geto, Z.; Molla, M.D.; Challa, F.; Belay, Y.; Getahun, T. Mitochondrial Dynamic Dysfunction as a Main Triggering Factor for Inflammation Associated Chronic Non-Communicable Diseases. J. Inflamm. Res. 2020, 13, 97-107. [CrossRef] [PubMed]

9. Gerdle, B.; Soderberg, K.; Salvador Puigvert, L.; Rosendal, L.; Larsson, B. Increased interstitial concentrations of pyruvate and lactate in the trapezius muscle of patients with fibromyalgia: A microdialysis study. J. Rehabil. Med. 2010, 42, 679-687. [CrossRef]

10. Gerdle, B.; Larsson, B.; Forsberg, F.; Ghafouri, N.; Karlsson, L.; Stensson, N.; Ghafouri, B. Chronic Widespread Pain: Increased Glutamate and Lactate Concentrations in the Trapezius Muscle and Plasma. Clin. J. Pain 2014, 30, 409-420. [CrossRef]

11. Gerdle, B.; Ernberg, M.; Mannerkorpi, K.; Larsson, B.; Kosek, E.; Christidis, N.; Ghafouri, B. Increased Interstitial Concentrations of Glutamate and Pyruvate in Vastus Lateralis of Women with Fibromyalgia Syndrome Are Normalized after an Exercise Intervention-A Case-Control Study. PLoS ONE 2016, 11, e0162010. [CrossRef]

12. Lundberg, P.; Harmsen, E.; Ho, C.; Vogel, H.J. Nuclear magnetic resonance studies of cellular metabolism. Anal. Biochem. 1990, 191, 193-222. [CrossRef]

13. Kemp, G.J.; Meyerspeer, M.; Moser, E. Absolute quantification of phosphorus metabolite concentrations in human muscle in vivo by 31P MRS: A quantitative review. NMR Biomed. 2007, 20, 555-565. [CrossRef]

14. Gerdle, B.; Forsgren, M.; Bengtsson, A.; Dahlqvist Leinhard, O.; Sören, B.; Karlsson, A.; Brandejsky, V.; Lund, E.; Lundberg, P. Decreased muscle concentrations of ATP and PCR in the quadriceps muscle of fibromyalgia patients-A 31P MRS study. Eur. J. Pain 2013, 17, 1205-1215. [CrossRef] 
15. Park, J.H.; Phothimat, P.; Oates, C.T.; Hernanz-Schulman, M.; Olsen, N.J. Use of P-31 magnetic resonance spectroscopy to detect metabolic abnormalities in muscles of patients with fibromyalgia. Arthritis Rheum. 1998, 41, 406-413. [CrossRef]

16. Dupont, W.; Plummer, W. Power and Sample Size Calculations: A Review and Computer Program. Control. Clin. Trials 1990, 11, 116-128. [CrossRef]

17. Rosendal, L.; Larsson, B.; Kristiansen, J.; Peolsson, M.; Søgaard, K.; Kjaer, M.; Sørensen, J.; Gerdle, B. Increase in muscle nociceptive substances and anaerobic metabolism in patients with trapezius myalgia: Microdialysis in rest and during exercise. Pain 2004, 112, 324-334. [CrossRef]

18. Wolfe, F.; Smythe, H.A.; Yunus, M.B.; Bennett, R.M.; Bombardier, C.; Goldenberg, D.L.; Tugwell, P.; Campbell, S.M.; Abeles, M.; Clark, P.; et al. The American College of Rheumatology 1990 Criteria for the Classification of Fibromyalgia. Report of the Multicenter Criteria Committee. Arthritis Rheum. 1990, 33, 160-172. [CrossRef]

19. Wolfe, F.; Clauw, D.J.; Fitzcharles, M.A.; Goldenberg, D.L.; Katz, R.S.; Mease, P.; Russell, A.S.; Russell, I.J.; Winfield, J.B.; Yunus, M.B. The American College of Rheumatology preliminary diagnostic criteria for fibromyalgia and measurement of symptom severity. Arthritis Care Res. 2010, 62, 600-610. [CrossRef]

20. Wolfe, F.; Clauw, D.J.; Fitzcharles, M.A.; Goldenberg, D.L.; Hauser, W.; Katz, R.S.; Mease, P.; Russell, A.S.; Russell, I.J.; Winfield, J.B. Fibromyalgia criteria and severity scales for clinical and epidemiological studies: A modification of the ACR Preliminary Diagnostic Criteria for Fibromyalgia. J. Rheumatol. 2011, 38, 1113-1122. [CrossRef]

21. Wolfe, F.; Clauw, D.J.; Fitzcharles, M.A.; Goldenberg, D.L.; Hauser, W.; Katz, R.L.; Mease, P.J.; Russell, A.S.; Russell, I.J.; Walitt, B. 2016 Revisions to the 2010/2011 fibromyalgia diagnostic criteria. Semin. Arthritis Rheum. 2016, 46, 319-329. [CrossRef]

22. Wallin, M.; Liedberg, G.; Borsbo, B.; Gerdle, B. Thermal detection and pain thresholds but not pressure pain thresholds are correlated with psychological factors in women with chronic whiplash-associated pain. Clin. J. Pain 2012, 28, 211-221. [CrossRef]

23. Lemming, D.; Borsbo, B.; Sjors, A.; Lind, E.B.; Arendt-Nielsen, L.; Graven-Nielsen, T.; Gerdle, B. Single-point but not tonic cuff pressure pain sensitivity is associated with level of physical fitness-A study of non-athletic healthy subjects. PLoS ONE 2015, 10, e0125432. [CrossRef] [PubMed]

24. Nordenskiöld, U.; Grimby, G. Grip force in patients with rheumatoid arthritis and fibromyalgia and in healthy subjects. A study with the Grippit instrument. Scand. J. Rheumatol. 1993, 22, 14-19. [CrossRef]

25. Åstrand, P.; Rodahl, K. Textbook of Work Physiology; McGraw-Hill: New York, NY, USA, 1986.

26. Csuka, M.; McCarty, D. Simple method for measurement of lower extremity muscle strength. Am. J. Med. 1985, 78, 77-81. [CrossRef]

27. Newcomer, K.; Krug, H.; Mahowald, M. Validity and reliability of the timed-stands test for patients with rheumatoid arthritis and other chronic diseases. J. Rheumatol. 1993, 20, 21-27. [PubMed]

28. Ruscheweyh, R.; Marziniak, M.; Stumpenhorst, F.; Reinholz, J.; Knecht, S. Pain sensitivity can be assessed by self-rating: Development and validation of the Pain Sensitivity Questionnaire. Pain 2009, 146, 65-74. [CrossRef] [PubMed]

29. Larsson, B.; Gerdle, B.; Bjork, J.; Grimby-Ekman, A. Pain Sensitivity and its Relation to Spreading on the Body, Intensity, Frequency, and Duration of Pain: A Cross-Sectional Population-Based Study (SwePain). Clin. J. Pain 2017, 33, 579-587. [CrossRef] [PubMed]

30. Kim, H.J.; Ruscheweyh, R.; Yeo, J.H.; Cho, H.G.; Yi, J.M.; Chang, B.S.; Lee, C.K.; Yeom, J.S. Translation, cross-cultural adaptation, and validity of the Korean version of the pain sensitivity questionnaire in chronic pain patients. Pain Pract. 2014, 14, 745-751. [CrossRef]

31. Ruscheweyh, R.; Verneuer, B.; Dany, K.; Marziniak, M.; Wolowski, A.; Colak-Ekici, R.; Schulte, T.L.; Bullmann, V.; Grewe, S.; Gralow, I.; et al. Validation of the pain sensitivity questionnaire in chronic pain patients. Pain 2012, 153, 1210-1218. [CrossRef]

32. Sellers, A.B.; Ruscheweyh, R.; Kelley, B.J.; Ness, T.J.; Vetter, T.R. Validation of the English language pain sensitivity questionnaire. Reg. Anesth. Pain Med. 2013, 38, 508-514. [CrossRef]

33. Valeberg, B.T.; Pedersen, L.M.; Girotto, V.; Christensen, V.L.; Stubhaug, A. Validation of the Norwegian Pain Sensitivity Questionnaire. J. Pain Res. 2017, 10, 1137-1142. [CrossRef]

34. Bjelland, I.; Dahl, A.A.; Haug, T.T.; Neckelmann, D. The validity of the Hospital Anxiety and Depression Scale. An updated literature review. J. Psychosom. Res. 2002, 52, 69-77. [CrossRef] 
35. Zigmond, A.S.; Snaith, R.P. The hospital anxiety and depression scale. Acta Psychiatr. Scand. 1983, 67, 361-370. [CrossRef] [PubMed]

36. LoMartire, R.; Ang, B.O.; Gerdle, B.; Vixner, L. Psychometric properties of Short Form-36 Health Survey, EuroQol 5-dimensions, and Hospital Anxiety and Depression Scale in patients with chronic pain. Pain 2020, 161, 83-95. [CrossRef]

37. Sullivan, M.J.; Bishop, S.R.; Pivik, J.R. The Pain Catastrophizing Scale: Development and Validation. Psychol. Assess. 1995, 7, 524-532. [CrossRef]

38. Miro, J.; Nieto, R.; Huguet, A. The Catalan version of the Pain Catastrophizing Scale: A useful instrument to assess catastrophic thinking in whiplash patients. J. Pain 2008, 9, 397-406. [CrossRef]

39. Bastien, C.H.; Vallieres, A.; Morin, C.M. Validation of the Insomnia Severity Index as an outcome measure for insomnia research. Sleep Med. 2001, 2, 297-307. [CrossRef]

40. Morin, C.M.; Belleville, G.; Belanger, L.; Ivers, H. The Insomnia Severity Index: Psychometric indicators to detect insomnia cases and evaluate treatment response. Sleep 2011, 34, 601-608. [CrossRef]

41. Chibnall, J.T.; Tait, R.C. The Pain Disability Index: Factor structure and normative data. Arch. Phys. Med. Rehabil. 1994, 75, 1082-1086. [CrossRef]

42. Tait, R.C.; Chibnall, J.T.; Krause, S. The Pain Disability Index: Psychometric properties. Pain 1990, 40, $171-182$. [CrossRef]

43. The EuroQol Group. EuroQol: A new facility for the measurement of health-related quality of life. Health Policy 1990, 16, 199-208. [CrossRef]

44. Brooks, R. EuroQol: The current state of play. Health Policy 1996, 37, 53-72. [CrossRef]

45. Hermens, H.; Fredriks, B. SENIAM The State of the Art on Sensors and Sensor Placement Procedures for Surface Elecromyography: A Proposal for Sensor Placement Procedures; Roessingh Research and Development: Enschede, The Netherlands, 1997.

46. Scheller, D.; Kolb, J. The internal reference technique in microdialysis: A practical approach to monitoring dialysis efficiency and to calculating tissue concentration from dialysate samples. J. Neurosci. Methods 1991, 40, 31-38. [CrossRef]

47. Hickner, R.; Bone, D.; Ungerstedt, U.; Jorfeldt, L.; Henriksson, J. Muscle blood flow during intermittent exercise: Comparison of the microdialysis ethanol technique and 133Xe clearance. Clin. Sci. (Lond.) 1994, 86, 15-25. [CrossRef]

48. Stallknecht, B.; Donsmark, M.; Enevoldsen, L.H.; Fluckey, J.D.; Galbo, H. Estimation of rat muscle blood flow by microdialysis probes perfused with ethanol, [14C]ethanol, and 3H2O. J. Appl. Physiol. 1999, 86, 1054-1061. [CrossRef]

49. Naressi, A.; Couturier, C.; Devos, J.M.; Janssen, M.; Mangeat, C.; de Beer, R.; Graveron-Demilly, D. Java-based graphical user interface for the MRUI quantitation package. MAGMA 2001, 12, 141-152. [CrossRef]

50. Vanhamme, L.; van den Boogaart, A.; Van Huffel, S. Improved method for accurate and efficient quantification of MRS data with use of prior knowledge. J. Magn. Reson. 1997, 129, 35-43. [CrossRef]

51. De Graaf, R. In Vivo NMR Spectroscopy: Principles and Techniques, 2nd ed.; John Wiley \& Sons: Chichester, UK, 2007.

52. Bogner, W.; Chmelik, M.; Schmid, A.I.; Moser, E.; Trattnig, S.; Gruber, S. Assessment of (31)P relaxation times in the human calf muscle: A comparison between $3 \mathrm{~T}$ and $7 \mathrm{~T}$ in vivo. Magn. Reson. Med. 2009, 62, 574-582. [CrossRef] [PubMed]

53. Ringqvist, Å.; Dragioti, E.; Björk, M.; Larsson, B.; Gerdle, B. Moderate and stable pain reductions as a result of Interdisciplinary Pain Rehabilitation-A cohort study from the Swedish Quality Registry for Pain Rehabilitation (SQRP). J. Clin. Med. 2019, 8, 905. [CrossRef] [PubMed]

54. Wheelock, A.M.; Wheelock, C.E. Trials and tribulations of 'omics data analysis: Assessing quality of SIMCA-based multivariate models using examples from pulmonary medicine. Mol. Biosyst. 2013, 9, 2589-2596. [CrossRef]

55. Eriksson, L.; Byrne, T.; Johansson, E.; Trygg, J.; Vikström, C. Multi-and Megavariate Data Analysis: Basic Principles and Applications, 3rd ed.; MKS Umetrics AB: Malmö, Sweden, 2013.

56. McCommis, K.S.; Finck, B.N. Mitochondrial pyruvate transport: A historical perspective and future research directions. Biochem. J. 2015, 466, 443-454. [CrossRef]

57. Brooks, G.A. The Science and Translation of Lactate Shuttle Theory. Cell Metab. 2018, 27, 757-785. [CrossRef] [PubMed] 
58. Schurr, A. Lactate, Not. Pyruvate, Is the End Product of Glucose Metabolism via Glycolysis. Carbohydrate 2017. [CrossRef]

59. Rogatzki, M.J.; Ferguson, B.S.; Goodwin, M.L.; Gladden, L.B. Lactate is always the end product of glycolysis. Front. Neurosci. 2015, 9, 22. [CrossRef] [PubMed]

60. Glancy, B.; Kane, D.A.; Kavazis, A.N.; Goodwin, M.L.; Willis, W.T.; Gladden, L.B. Mitochondrial lactate metabolism: History and implications for exercise and disease. J. Physiol. 2020. [CrossRef]

61. Layec, G.; Trinity, J.D.; Hart, C.R.; Kim, S.E.; Groot, H.J.; Le Fur, Y.; Sorensen, J.R.; Jeong, E.K.; Richardson, R.S. Impact of age on exercise-induced ATP supply during supramaximal plantar flexion in humans. Am. J. Physiol. Regul. Integr. Comp. Physiol. 2015, 309, R378-R388. [CrossRef]

62. Hargreaves, M.; Spriet, L.L. Skeletal muscle energy metabolism during exercise. Nat. Metab. 2020, 2, 817-828. [CrossRef]

63. Li, M.; Chen, F.; Wang, H.; Wu, W.; Zhang, X.; Tian, C.; Yu, H.; Liu, R.; Zhu, B.; Zhang, B.; et al. Non-invasive assessment of phosphate metabolism and oxidative capacity in working skeletal muscle in healthy young Chinese volunteers using (31)P Magnetic Resonance Spectroscopy. PeerJ 2016, 4, e2259. [CrossRef] [PubMed]

64. Gouspillou, G.; Bourdel-Marchasson, I.; Rouland, R.; Calmettes, G.; Biran, M.; Deschodt-Arsac, V.; Miraux, S.; Thiaudiere, E.; Pasdois, P.; Detaille, D.; et al. Mitochondrial energetics is impaired in vivo in aged skeletal muscle. Aging Cell 2014, 13, 39-48. [CrossRef] [PubMed]

65. Sanchez-Dominguez, B.; Bullon, P.; Roman-Malo, L.; Marin-Aguilar, F.; Alcocer-Gomez, E.; Carrion, A.M.; Sanchez-Alcazar, J.A.; Cordero, M.D. Oxidative stress, mitochondrial dysfunction and, inflammation common events in skin of patients with Fibromyalgia. Mitochondrion 2015, 21, 69-75. [CrossRef]

66. Bazzichi, L.; Giannaccini, G.; Betti, L.; Fabbrini, L.; Schmid, L.; Palego, L.; Giacomelli, C.; Rossi, A.; Giusti, L.; De Feo, F.; et al. ATP, calcium and magnesium levels in platelets of patients with primary fibromyalgia. Clin. Biochem. 2008, 41, 1084-1090. [CrossRef]

67. García, J.; Carvajal-Gil, J.; Herrero-Olea, A.; Gómez-Galán, R. Altered Inflammatory Mediators in Fibromyalgia. Rheumatology 2017, 7. [CrossRef]

68. Weibel, E.R.; Hoppeler, H. Exercise-induced maximal metabolic rate scales with muscle aerobic capacity. J. Exp. Biol. 2005, 208, 1635-1644. [CrossRef]

69. Picard, M.; Gentil, B.J.; McManus, M.J.; White, K.; St Louis, K.; Gartside, S.E.; Wallace, D.C.; Turnbull, D.M. Acute exercise remodels mitochondrial membrane interactions in mouse skeletal muscle. J. Appl. Physiol. (1985) 2013, 115, 1562-1571. [CrossRef]

70. Hood, D.A.; Memme, J.M.; Oliveira, A.N.; Triolo, M. Maintenance of Skeletal Muscle Mitochondria in Health, Exercise, and Aging. Annu. Rev. Physiol. 2019, 81, 19-41. [CrossRef] [PubMed]

71. Bengtsson, A. Editorial, The muscle in fibromyalgia. Rheumatology 2002, 41, 721-724. [CrossRef]

72. Bengtsson, A.; Henriksson, K.G.; Larsson, J. Muscle biopsy in primary fibromyalgia. Light-microscopical and histochemical findings. Scand. J. Rheumatol. 1986, 15, 1-6. [PubMed]

73. Lindh, M.; Johansson, G.; Hedberg, M.; Henning, G.B.; Grimby, G. Muscle fiber characteristics, capillaries and enzymes in patients with fibromyalgia and controls. Scand. J. Rheumatol. 1995, 24, 34-37. [CrossRef]

74. Drewes, A.M.; Andreasen, A.; Schroder, H.D.; Hogsaa, B.; Jennum, P. Pathology of skeletal muscle in fibromyalgia: A histo-immuno-chemical and ultrastructural study. Br. J. Rheumatol. 1993, 32, 479-483. [CrossRef]

75. Jacobsen, S.; Bartels, E.M.; Danneskiold-Samsoe, B. Single cell morphology of muscle in patients with chronic muscle pain. Scand. J. Rheumatol. 1991, 20, 336-343. [CrossRef]

76. De Meulemeester, K.; Cagnie, B.; Van Dorpe, J.; Lammens, M.; Petrovic, M.; Calders, P. Differences in the Mitochondrial and Lipid Droplet Morphology in Female Office Workers With Trapezius Myalgia, Compared with Healthy Controls: A Muscle Biopsy Study. Am. J. Phys. Med. Rehabil. 2019, 98, 989-997. [CrossRef]

77. Tan, E.C.; Janssen, A.J.; Roestenberg, P.; van den Heuvel, L.P.; Goris, R.J.; Rodenburg, R.J. Mitochondrial dysfunction in muscle tissue of complex regional pain syndrome type I patients. Eur. J. Pain 2011, 15, 708-715. [PubMed]

78. Niyazov, D.M.; Kahler, S.G.; Frye, R.E. Primary Mitochondrial Disease and Secondary Mitochondrial Dysfunction: Importance of Distinction for Diagnosis and Treatment. Mol. Syndromol. 2016, 7, 122-137. [CrossRef] 
79. Olausson, P.; Gerdle, B.; Ghafouri, N.; Sjostrom, D.; Blixt, E.; Ghafouri, B. Protein alterations in women with chronic widespread pain-An explorative proteomic study of the trapezius muscle. Sci. Rep. 2015, 5, 11894. [CrossRef] [PubMed]

80. Menzies, V.; Starkweather, A.; Yao, Y.; Thacker, L.R., 2nd; Garrett, T.J.; Swift-Scanlan, T.; Kelly, D.L.; Patel, P.; Lyon, D.E. Metabolomic Differentials in Women With and Without Fibromyalgia. Clin. Transl. Sci. 2020, 13, 67-77. [CrossRef]

81. Malatji, B.G.; Meyer, H.; Mason, S.; Engelke, U.F.H.; Wevers, R.A.; van Reenen, M.; Reinecke, C.J. A diagnostic biomarker profile for fibromyalgia syndrome based on an NMR metabolomics study of selected patients and controls. BMC Neurol. 2017, 17, 88. [CrossRef]

82. Malatji, B.G.; Mason, S.; Mienie, L.J.; Wevers, R.A.; Meyer, H.; van Reenen, M.; Reinecke, C.J. The GC-MS metabolomics signature in patients with fibromyalgia syndrome directs to dysbiosis as an aspect contributing factor of FMS pathophysiology. Metabolomics 2019, 15, 54. [CrossRef] [PubMed]

83. Ghafouri, N.; Ghafouri, B.; Larsson, B.; Stensson, N.; Fowler, C.J.; Gerdle, B. Palmitoylethanolamide and stearoylethanolamide levels in the interstitium of the trapezius muscle of women with chronic widespread pain and chronic neck-shoulder pain correlate with pain intensity and sensitivity. Pain 2013, 154, 1649-1658. [CrossRef]

84. Stensson, N.; Gerdle, B.; Ernberg, M.; Mannerkorpi, K.; Kosek, E.; Ghafouri, B. Increased Anandamide and Decreased Pain and Depression after Exercise in Fibromyalgia. Med. Sci. Sports Exerc. 2020, 52, 1617-1628. [CrossRef]

85. Jablochkova, A.; Backryd, E.; Kosek, E.; Mannerkorpi, K.; Ernberg, M.; Gerdle, B.; Ghafouri, B. Unaltered low nerve growth factor and high brain-derived neurotrophic factor levels in plasma from patients with fibromyalgia after a 15-week progressive resistance exercise. J. Rehabil. Med. 2019, 51, 779-787. [CrossRef]

86. Ernberg, M.; Christidis, N.; Ghafouri, B.; Bileviciute-Ljungar, I.; Lofgren, M.; Larsson, A.; Palstam, A.; Bjersing, J.; Mannerkorpi, K.; Kosek, E.; et al. Effects of 15 weeks of resistance exercise on pro-inflammatory cytokine levels in the vastus lateralis muscle of patients with fibromyalgia. Arthritis Res. Ther. 2016, 18, 137. [CrossRef]

87. Wahlen, K.; Ernberg, M.; Kosek, E.; Mannerkorpi, K.; Gerdle, B.; Ghafouri, B. Significant correlation between plasma proteome profile and pain intensity, sensitivity, and psychological distress in women with fibromyalgia. Sci. Rep. 2020, 10, 12508. [CrossRef] [PubMed]

88. Wåhlén, K.; Olausson, P.; Carlsson, A.; Ghafouri, N.; Gerdle, B. Systemic alteration of plasma proteins from women with chronic widespread pain compared to healthy controls; a proteomic study. J. Pain Res. 2017, 10, 797-809. [CrossRef] [PubMed]

89. Han, C.L.; Sheng, Y.C.; Wang, S.Y.; Chen, Y.H.; Kang, J.H. Serum proteome profiles revealed dysregulated proteins and mechanisms associated with fibromyalgia syndrome in women. Sci. Rep. 2020, 10, 12347. [CrossRef]

90. Vaamonde-Garcia, C.; Lopez-Armada, M.J. Role of mitochondrial dysfunction on rheumatic diseases. Biochem. Pharmacol. 2019, 165, 181-195. [CrossRef] [PubMed]

91. Groen, M.B.; Knudsen, T.A.; Finsen, S.H.; Pedersen, B.K.; Hellsten, Y.; Mortensen, S.P. Reduced skeletal-muscle perfusion and impaired ATP release during hypoxia and exercise in individuals with type 2 diabetes. Diabetologia 2019, 62, 485-493. [CrossRef] [PubMed]

92. Kulshreshtha, P.; Deepak, K.K. Autonomic nervous system profile in fibromyalgia patients and its modulation by exercise: A mini review. Clin. Physiol. Funct. Imaging 2013, 33, 83-91. [CrossRef]

93. Shang, Y.; Gurley, K.; Symons, B.; Long, D.; Srikuea, R.; Crofford, L.J.; Peterson, C.A.; Yu, G. Noninvasive optical characterization of muscle blood flow, oxygenation, and metabolism in women with fibromyalgia. Arthritis Res. Ther. 2012, 14, R236. [CrossRef]

94. Nelson, N.L. Muscle strengthening activities and fibromyalgia: A review of pain and strength outcomes. J. Bodyw. Mov. Ther. 2015, 19, 370-376. [CrossRef]

95. Umay, E.; Gundogdu, I.; Ozturk, E.A. What happens to muscles in fibromyalgia syndrome. Ir. J. Med. Sci. 2020, 189, 749-756. [CrossRef]

96. Hood, D.A.; Tryon, L.D.; Carter, H.N.; Kim, Y.; Chen, C.C. Unravelling the mechanisms regulating muscle mitochondrial biogenesis. Biochem. J. 2016, 473, 2295-2314. [CrossRef] 
97. Hauser, W.; Klose, P.; Langhorst, J.; Moradi, B.; Steinbach, M.; Schiltenwolf, M.; Busch, A. Efficacy of different types of aerobic exercise in fibromyalgia syndrome: A systematic review and meta-analysis of randomised controlled trials. Arthritis Res. Ther. 2010, 12, R79. [CrossRef]

98. Sosa-Reina, M.D.; Nunez-Nagy, S.; Gallego-Izquierdo, T.; Pecos-Martin, D.; Monserrat, J.; Alvarez-Mon, M. Effectiveness of Therapeutic Exercise in Fibromyalgia Syndrome: A Systematic Review and Meta-Analysis of Randomized Clinical Trials. Biomed. Res. Int. 2017, 2017, 2356346. [CrossRef] [PubMed]

99. Padrao, A.I.; Ferreira, R.; Amado, F.; Vitorino, R.; Duarte, J.A. Uncovering the exercise-related proteome signature in skeletal muscle. Proteomics 2016, 16, 816-830. [CrossRef] [PubMed]

100. Kras, K.A.; Hoffman, N.; Roust, L.R.; Benjamin, T.R.; De Filippis, E.A.; Katsanos, C.S. Adenosine Triphosphate Production of Muscle Mitochondria after Acute Exercise in Lean and Obese Humans. Med. Sci. Sports Exerc. 2019, 51, 445-453. [CrossRef] [PubMed]

101. Elert, J.; Aspegren Kendall, S.; Larsson, B.; Månsson, B.; Gerdle, B. Chronic pain and difficulty in relaxing postural muscles in patients with fibromylgia and chronic whiplash associated disorders. J. Rheumatol. 2001, 28, 1361-1368. [PubMed]

102. Gerdle, B.; Grönlund, C.; Karlsson, S.; Holtermann, A.; Roeleveld, K. Altered neuromuscular control mechanisms of the trapezius muscle in fibromyalgia. BMC Musculoskelet. Disord. 2010, 11, 42. [CrossRef]

103. Bazzichi, L.; Dini, M.; Rossi, A.; Corbianco, S.; De Feo, F.; Giacomelli, C.; Zirafa, C.; Ferrari, C.; Rossi, B.; Bombardieri, S. Muscle modifications in fibromyalgic patients revealed by surface electromyography (SEMG) analysis. BMC Musculoskelet. Disord. 2009, 10, 36. [CrossRef]

104. Falla, D.; Andersen, H.; Danneskiold-Samsøe, B.; Arendt-Nielsen, L.; Farina, D. Adaptations of upper trapezius muscle activity during sustained contractions in women with fibromyalgia. J. Electromyogr. Kinesiol. 2010, 20, 457-464. [CrossRef]

105. de Paoli, F.V.; Ortenblad, N.; Pedersen, T.H.; Jorgensen, R.; Nielsen, O.B. Lactate per se improves the excitability of depolarized rat skeletal muscle by reducing the $\mathrm{Cl}$ - conductance. J. Physiol. 2010, 588, 4785-4794. [CrossRef]

106. van Hall, G. Lactate kinetics in human tissues at rest and during exercise. Acta Physiol. 2010, 199, 499-508. [CrossRef]

107. Olausson, P.; Ghafouri, B.; Ghafouri, N.; Gerdle, B. Specific proteins of the trapezius muscle correlate with pain intensity and sensitivity-An explorative multivariate proteomic study of the trapezius muscle in women with chronic widespread pain. J. Pain Res. 2016, 9, 345-356. [CrossRef] [PubMed]

108. Wahlen, K.; Ghafouri, B.; Ghafouri, N.; Gerdle, B. Plasma Protein Pattern Correlates with Pain Intensity and Psychological Distress in Women with Chronic Widespread Pain. Front. Psychol. 2018, 9, 2400. [CrossRef]

109. Gerdle, B.; Ghafouri, B.; Ghafouri, N.; Bäckryd, E.; Gordh, T. Signs of ongoing inflammation in female patients with chronic widespread pain-A multivariate, explorative, cross-sectional study of blood samples. Medicine 2017, 96, e6130. [CrossRef]

110. Palmer, S.; Bailey, J.; Brown, C.; Jones, A.; McCabe, C.S. Sensory Function and Pain Experience in Arthritis, Complex Regional Pain Syndrome, Fibromyalgia Syndrome, and Pain-Free Volunteers: A Cross-Sectional Study. Clin. J. Pain 2019, 35, 894-900. [CrossRef]

111. Goubert, D.; Danneels, L.; Graven-Nielsen, T.; Descheemaeker, F.; Meeus, M. Differences in Pain Processing Between Patients with Chronic Low Back Pain, Recurrent Low Back Pain, and Fibromyalgia. Pain Physician 2017, 20, 307-318.

112. Potvin, S.; Marchand, S. Pain facilitation and pain inhibition during conditioned pain modulation in fibromyalgia and in healthy controls. Pain 2016, 157, 1704-1710. [CrossRef]

113. O’Brien, A.T.; Deitos, A.; Trinanes Pego, Y.; Fregni, F.; Carrillo-de-la-Pena, M.T. Defective Endogenous Pain Modulation in Fibromyalgia: A Meta-Analysis of Temporal Summation and Conditioned Pain Modulation Paradigms. J. Pain 2018, 19, 819-836. [CrossRef]

114. Gerdle, B.; Wahlen, K.; Ghafouri, B. Plasma protein patterns are strongly correlated with pressure pain thresholds in women with chronic widespread pain and in healthy controls-an exploratory case-control study. Medicine 2020, 99, e20497. [CrossRef]

115. van den Ameele, J.; Fuge, J.; Pitceathly, R.D.S.; Berry, S.; McIntyre, Z.; Hanna, M.G.; Lee, M.; Chinnery, P.F. Chronic pain is common in mitochondrial disease. Neuromuscul. Disord. 2020, 30, 413-419. [CrossRef]

116. Cruz, R.S.; de Aguiar, R.A.; Turnes, T.; Penteado Dos Santos, R.; de Oliveira, M.F.; Caputo, F. Intracellular shuttle: The lactate aerobic metabolism. Sci. World J. 2012, 2012, 420984. [CrossRef] 
117. Lanza, I.R.; Nair, K.S. Mitochondrial function as a determinant of life span. Pflugers Arch. 2010, 459, $277-289$. [CrossRef] [PubMed]

118. Barbieri, E.; Sestili, P. Reactive oxygen species in skeletal muscle signaling. J. Signal Transduct. 2012, 2012, 982794. [CrossRef] [PubMed]

119. Kallenborn-Gerhardt, W.; Schroder, K.; Geisslinger, G.; Schmidtko, A. NOXious signaling in pain processing. Pharmacol. Ther. 2013, 137, 309-317. [CrossRef]

120. Ponnalagu, D.; Singh, H. Insights Into the Role of Mitochondrial Ion Channels in Inflammatory Response. Front. Physiol. 2020, 11, 258. [CrossRef] [PubMed]

121. Angajala, A.; Lim, S.; Phillips, J.B.; Kim, J.H.; Yates, C.; You, Z.; Tan, M. Diverse Roles of Mitochondria in Immune Responses: Novel Insights Into Immuno-Metabolism. Front. Immunol. 2018, 9, 1605. [CrossRef]

122. De Lavera, I.; Pavon, A.D.; Paz, M.V.; Oropesa-Avila, M.; de la Mata, M.; Alcocer-Gomez, E.; Garrido-Maraver, J.; Cotan, D.; Alvarez-Cordoba, M.; Sanchez-Alcazar, J.A. The Connections Among Autophagy, Inflammasome and Mitochondria. Curr. Drug Targets 2017, 18, 1030-1038. [CrossRef]

123. Cordero, M.D.; Diaz-Parrado, E.; Carrion, A.M.; Alfonsi, S.; Sanchez-Alcazar, J.A.; Bullon, P.; Battino, M.; de Miguel, M. Is inflammation a mitochondrial dysfunction-dependent event in fibromyalgia? Antioxid. Redox Signal. 2013, 18, 800-807. [CrossRef]

124. Meeus, M.; Nijs, J.; Hermans, L.; Goubert, D.; Calders, P. The role of mitochondrial dysfunctions due to oxidative and nitrosative stress in the chronic pain or chronic fatigue syndromes and fibromyalgia patients: Peripheral and central mechanisms as therapeutic targets? Expert Opin. Ther. Targets 2013, 17, 1081-1089. [CrossRef]

125. Cordero, M.D.; Alcocer-Gomez, E.; Culic, O.; Carrion, A.M.; de Miguel, M.; Diaz-Parrado, E.; Perez-Villegas, E.M.; Bullon, P.; Battino, M.; Sanchez-Alcazar, J.A. NLRP3 inflammasome is activated in fibromyalgia: The effect of coenzyme Q10. Antioxid. Redox Signal. 2014, 20, 1169-1180. [CrossRef]

126. Cowie, A.M.; Dittel, B.N.; Stucky, C.L. A Novel Sex-Dependent Target for the Treatment of Postoperative Pain: The NLRP3 Inflammasome. Front. Neurol. 2019, 10, 622. [CrossRef]

127. Zhang, H.; Li, F.; Li, W.W.; Stary, C.; Clark, J.D.; Xu, S.; Xiong, X. The inflammasome as a target for pain therapy. Br. J. Anaesth. 2016, 117, 693-707. [CrossRef] [PubMed]

128. Andres-Rodriguez, L.; Borras, X.; Feliu-Soler, A.; Perez-Aranda, A.; Angarita-Osorio, N.; Moreno-Peral, P.; Montero-Marin, J.; Garcia-Campayo, J.; Carvalho, A.F.; Maes, M.; et al. Peripheral immune aberrations in fibromyalgia: A systematic review, meta-analysis and meta-regression. Brain Behav. Immun. 2020, 87, 881-889. [CrossRef] [PubMed]

129. Goncalves Dos Santos, G.; Delay, L.; Yaksh, T.L.; Corr, M. Neuraxial Cytokines in Pain States. Front. Immunol. 2019, 10, 3061. [CrossRef] [PubMed]

130. Ramirez-Tejero, J.A.; Martinez-Lara, E.; Rus, A.; Camacho, M.V.; Del Moral, M.L.; Siles, E. Insight into the biological pathways underlying fibromyalgia by a proteomic approach. J. Proteom. 2018, 186, 47-55. [CrossRef] [PubMed]

131. Suppers, A.; van Gool, A.J.; Wessels, H. Integrated Chemometrics and Statistics to Drive Successful Proteomics Biomarker Discovery. Proteomes 2018, 6, 20. [CrossRef] [PubMed]

Publisher's Note: MDPI stays neutral with regard to jurisdictional claims in published maps and institutional affiliations.

(C) 2020 by the authors. Licensee MDPI, Basel, Switzerland. This article is an open access article distributed under the terms and conditions of the Creative Commons Attribution (CC BY) license (http://creativecommons.org/licenses/by/4.0/). 